JOURNAL OF ENGINEERING THERMOPHYSICS

https://www.springer.com/journal/11823

Electronic - ISSN 1990-5432; Print ISSN- 1810-2328

Accepted April 6 2020

\title{
MATHEMATICAL MODELLING OF TRIPLE DIFFUSION IN NATURAL CONVECTION FLOW IN A VERTICAL DUCT WITH ROBIN BOUNDARY CONDITIONS, VISCOUS HEATING AND CHEMICAL REACTION EFFECTS
}

\author{
J.C. Umavathi * \\ Visiting Professor, Dipartimento di Ingegneria dell'Università degli Studi della Campania "Luigi Vanvitelli", Via Roma 29, Aversa (CE), Italy. \\ Email: drumavathi@rediffmail.com \\ O. Anwar Bég \\ Professor of Engineering Science \& Director -Multi-Physical Engineering Sciences Group (MPESH), Department of Aeronautical/Mechanical \\ Engineering, University of Salford, Manchester, M5 4WT, UK. \\ Email: 0.A.Beg@salford.ac.uk \\ ${ }^{*}$ Corresponding author; On leave from Department of Mathematics, Gulbarga University, Gulbarga-585 106, Karnataka, India.
}

\section{ABSTRACT:}

The triple-diffusive convective flow (thermal diffusion and dual species diffusion) in a viscous fluid flowing within a vertical duct is investigated subject to Robin boundary conditions at the duct walls. Viscous heating and homogenous chemical reaction effects are included. The mass transfer (solutal) buoyancy effects due to concentration gradients of the dispersed components are taken into account using the Boussinesq approximation. Symmetric and asymmetric wall conditions for the temperature are taken into account. The conservation equations are rendered into dimensionless form via suitable transformations and the emerging ordinary differential equations feature a number of dimensionless parameters including thermal Grashof number, two solutal Grashof numbers (one for each of the diffusing components i.e. species 1 and species 2), left and right duct wall thermal Biot numbers, species 1 and species 2 chemical reaction parameters, Brinkman number and temperature difference ratio. These coupled and nonlinear dimensionless conservation equations are solved numerically using the Runge-Kutta shooting method. The solutions obtained numerically are validated with approximate analytical solutions obtained via a regular perturbation method which are valid for small values of Brinkman number. The impact of selected parameters on velocity, temperature and dual species concentration distributions is visualized graphically. Furthermore, the variation of skin friction and Nusselt number with these parameters is also tabulated. The solutions obtained numerically and analytically are found to be equal in the absence of viscous dissipation. However, the deviation is magnified with large values of Brinkman number. In the absence of chemical reaction, the results concur with the earlier computations of Zanchini (1998). Increasing second species solutal Grashof number is observed to decelerate the flow in the left duct half space, to accelerate the flow in the right duct half space and consistently reduce temperatures across the entire duct width. With increasing species 1 chemical reaction parameter the concentration magnitudes are elevated in the left duct half space whereas they are depressed in the right duct half space. A similar response is computed for the influence of species 2 reaction parameter on the concentration profile. Temperatures are strongly enhanced across the duct width with increasing Brinkman number and are symmetric in nature about the channel centerline for the symmetric Biot number case (equal thermal Biot numbers at the left and right walls). These profiles are morphed for the asymmetric Biot number case (equal thermal Biot numbers at the left and right walls). Temperatures descend from the left wall to the right wall, although they are still enhanced with increasing Brinkman number. The simulations are relevant to geochemical transport phenomena, industrial materials processing and thermal duct design.

KEYWORDS: Robin boundary conditions, triple diffusive convection, dual species diffusion, mass transfer, numerical, perturbation method, thermal Biot number, Brinkman number. 


\section{List of Symbols}

A constant

$B i_{1}, B i_{2}$ thermal Biot numbers at the left and right wall of the duct

$\mathrm{Br} \quad$ Brinkman number

$c_{p} \quad$ specific heat

$D \quad$ hydraulic diameter

g gravity

$\Lambda_{1} \quad$ thermal Grashof number

$\Lambda_{2} \quad$ solute Grashof number (for species 1)

$\Lambda_{3} \quad$ solute Grashof number (for species 2)

$h_{1}, h_{2}$ heat transfer coefficient

$K \quad$ thermal conductivity of the fluid

$K_{m} \quad$ dimensional chemical reaction parameter

L channel width

$N u_{1}, N u_{2} \quad$ Nusselt numbers

$P \quad$ Pressure $\left(P=p+\rho_{0} g X\right.$ i.e. hydrostatic pressure + pressure difference $)$

Re Reynolds number 
$R_{T} \quad$ ratio of temperature difference

$S \quad$ dimensionless parameter (function of left and right wall thermal Biot numbers)

$T \quad$ temperature

$T_{1}, T_{2}$ temperatures of the external fluid at the left and right wall of the duct

$T_{0} \quad$ reference temperature

$u \quad X$-direction velocity in non-dimensional form

$U \quad X$-direction velocity in dimensional form

$U_{0} \quad$ reference velocity

X coordinate

$y \quad$ coordinate in dimensionless form

$Y \quad$ coordinate in dimensional form

\section{Greek symbols}

$\alpha_{1} \quad$ chemical reaction parameter (for species 1)

$\alpha_{2} \quad$ chemical reaction parameter (for species 2)

$\beta_{T} \quad$ thermal expansion coefficient

$\beta_{C 1} \quad$ concentration expansion coefficient

$\beta_{C 2} \quad$ concentration expansion coefficient

$\Delta T \quad$ reference temperature difference 
$\varepsilon \quad$ dimensionless parameter

$\theta \quad$ dimensionless temperature

$\phi_{1} \quad$ dimensionless concentration (for species 1)

$\phi_{2} \quad$ dimensionless concentration (for species 2)

$\rho \quad$ density of the fluid

$\rho_{0} \quad$ value of the mass density when $T=T_{0}$

$\mu \quad$ dynamic viscosity of the fluid

$v \quad$ kinematic viscosity of the fluid

\section{INTRODUCTION}

Forced convection is induced in fluids owing to some external forces whereas free (natural) convection occurs by the difference in temperature of the fluid at different locations. In the presence of gravity, buoyancy forces are generated due to the density differences apart and act simultaneously with viscous forces. When the buoyancy forces and viscous forces are of comparable magnitude, then the convective process is usually termed mixed convection. Both natural and mixed convection flows arise under large wall fluid temperature differences and also under moderate flow velocities. They feature in geophysical systems, energy production (solar and geothermal), architectural fluid dynamics and semi-conductor melt materials processing [1]. The buoyancy forces arising from concentration differences and from temperature differences play an important role in mixed convective flows when the concentration and temperature differences are large and the flow velocity is relatively small. 
Numerous technological systems (including combustion processes, cooling towers, metallurgical flows, spray coating, drying processes etc.) also require a comprehensive understanding of simultaneous heat and mass transfer in the presence of chemical reactions. Many researchers have investigated such flows which can also be accompanied with other phenomena (magnetic fields, non-Newtonian behavior, multimode heat transfer etc) and a variety of chemical reaction types have been addressed. Anjalidevi and Kandasamy [2] studied homogenous destructive first order chemical reaction in double-diffusive boundary layer convection flow. Muthucumaraswamy et al. [3] investigated radiative flux effects in reactive natural convection flows from a mobile plate. Mehmood et al. [4] analyzed thermal relaxation and heterogenous chemical reaction effects in magnetized viscoelastic polymer non-orthogonal stagnation flow with applications in smart coating systems synthesis. Further studies of reactive multi-physical flows include Takhar et al. [5] (on Sakiadis stretching hydromagnetic thermosolutal boundary layers), Shamshuddin et al. [6] (bioconvection magnetic lubricants for corrosion mitigation), Ibrahim et al [7] (who also studied heat generation and transient magnetohydrodynamic radiative flow) and Shamshuddin et al. [8] (on double-diffusive reactive micropolar transport from a tilted surface). Extensive other studies of reactive buoyancy-driven flows have been reviewed by Gebhart et al. [9]. Double-diffusion problems in vertical ducts are particularly relevant to geophysical flows and many elaborate studies have been communicated in this regard. Umavathi et al. [10] investigated micropolar mixed convection with heat generation/absorption effects in a vertical duct. Liu and Umavathi [11] studied natural convection of micropolar fluids in a porous medium duct. Umavathi and Mohite [12] analyzed variable thermophysical property effects in nanofluid flow in a duct filled with permeable material with cross diffusion effects. Umavathi and Sheremet [13] investigated the stability of doublediffusive convection in micropolar nanofluid-saturated porous media.

While double-diffusive convection involves simultaneous thermal convective heat and mass transfer with a single diffusing species, triple diffusion relates to the case where two unique species are present in the flow in addition to heat. Triple diffusive convection has relevant applications in geohydrology and also stratospheric heating. Further 
applications include dyes, materials fabrication processes and contaminant transport where the chemical species (contaminants) may be reactive or non-reactive (Celia et al. [14], Chen et al. [15]). Griffiths [16] presented a pioneering study on stability of triple diffusion in a horizontal fluid layer with free boundary conditions. Experimental work was also done by Griffiths [17] on triple diffusive convection in a horizontal fluid layer. Further Griffiths [18] also measured the flux for a three-component thermohaline interface, utilizing $\mathrm{KCl}, \mathrm{NaCl}$ and $\mathrm{MgCl}_{2}$ salts where the fluid layer was heated from below and cooled from above. Later using Griffiths [16] model, Rudraiah and Vortmeyer [19] and Poulikakos [20] further examined the stability of triple diffusive convection in a porous matrix. Pearlstein et al. [21] also discussed the triple diffusion in a viscous fluid. Triple diffusion was also discussed by Khan et al. [22] for the case of a nanofluidsaturated porous matrix. Linear and nonlinear stability analysis for triple diffusion in a couple stress fluid was explored by Shivakumara and Naveen Kumar [23]. Prakash et al. [24] also studied the stability of triple diffusion in a fluid layer rotating vertically with a uniform velocity. Recently Ghalambaz et al. [25] simulated the convective triple diffusive heat transfer in a three-component solution within an enclosure using a finite element method.

In the majority of these studies, mathematical models have been developed principally with boundary conditions either of the first or second kind. Relatively few investigations have been communicated employing the so-called Robin boundary conditions i.e. of the third kind (convective heat exchange between the surface and the surrounding fluid). Such boundary conditions emerge in many diverse industrial and engineering applications including phase change phenomena, condenser design, material drying, heat exchangers and transpiration cooling processes. Wibulswas [26] studied heat transfer in the thermal entrance region of a rectangular channel using temperature boundary conditions of the first kind. Hicken [27] employed temperature boundary conditions of the second kind. However, boundary conditions of third kind (Robin type), in which the local wall heat flux is a linear function of the local wall temperature, are generally more realistic for engineering designs. Using Robin boundary conditions, Javeri [28] computed the laminar heat transfer in the thermal entrance region of a rectangular 
channel. Zanchini [29] analyzed the influence of viscous dissipation on convective flow in a vertical duct with boundary conditions of the third kind. Subsequently Umavathi et al. [30-35] studied flow and heat transfer in vertical ducts with Robin boundary conditions, for a variety of multi-physics effects (heat generation, non-Darcy porous media, micropolar fluids, magnetohydrodynamics and immiscible fluids).

The focus of the present article is to investigate triple diffusive convection flow of chemically reacting viscous fluid flowing in a vertical duct using boundary conditions of the third kind. To the authors' knowledge this constitutes the first attempt to simulate triple diffusive convection in reactive dissipative flows using boundary conditions of third kind. Detailed mathematical analysis is included for the transformed boundary value problem. Two diffusing and reactive species are considered. A regular perturbation method is employed in addition to a Runge-Kutta shooting method. Both cases of symmetric and asymmetric reference temperatures of the external fluid (equal and unequal duct wall thermal Biot numbers) are considered. Extensive graphical plots are presented examining the impact of key parameters on velocity, temperature and dual species concentration distributions. The present results are shown to agree with Zanchini [29] in the absence of mass (solutal) and thermal Grashof numbers. The study is relevant to materials processing systems, geo-reactive environmental flows and chemical engineering.

\section{MATHEMATICAL FORMULATION}

The problem under study comprises buoyancy-driven triple diffusive convection in a viscous Newtonian fluid in a vertical duct. The flow is assumed to be steady and laminar. The $X$-axis of the duct is chosen in the opposite direction to gravity. The $Y$ axis is taken to be orthogonal to the walls of the duct. The distance between the walls is $2 b$ and the origin is located at the centerline of the duct. The flow in the duct is owing to

the buoyancy forces. Velocity is taken as zero on the walls of the duct i.e. the no-slip condition is imposed. The viscosity, heat conductivity, heat diffusivity and heat expansion co-efficient are assumed to be constant. The walls of the duct are infinite along the axial plane and hence velocity depends only on $Y$. The equation of state and 
Boussinesq approximation are taken into consideration. $T_{0}$ is the ambient fluid temperature and $C_{01}, C_{02}$ are the ambient concentrations of the two reactive species, respectively. A first order homogenous destructive chemical reaction is assumed for both species. The concentration of diffusing species is assumed to be very small in comparison with the other chemical species. Hence Dufour and Soret effects are neglected. The equation of state and Boussinesq approximation are taken into consideration i.e. $\rho=\rho_{0} g \beta_{T}\left(T-T_{0}\right)+\rho_{0} g \beta_{C_{1}}\left(C_{1}-C_{01}\right)+\rho_{0} g \beta_{C_{2}}\left(C_{2}-C_{02}\right)$. The conservation equations for the momentum, energy and dual species mass transfer are given by:

$$
\begin{aligned}
& \rho_{0} g \beta_{T}\left(T-T_{0}\right)+\rho_{0} g \beta_{C_{1}}\left(C_{1}-C_{01}\right)+\rho_{0} g \beta_{C_{2}}\left(C_{2}-C_{02}\right)-\frac{\partial p}{\partial X}+\mu \frac{d^{2} U}{d Y^{2}}=0 \\
& K \frac{d^{2} T}{d Y^{2}}+\mu\left(\frac{d U}{d Y}\right)^{2}=0 \\
& D_{m 1} \frac{d^{2} C_{1}}{d Y^{2}}-K_{1} C_{1}=0 \\
& D_{m 2} \frac{d^{2} C_{2}}{d Y^{2}}-K_{2} C_{2}=0
\end{aligned}
$$

The velocity, temperature and dual species concentration boundary conditions are taken as:

$$
\begin{aligned}
& U\left(\frac{-L}{2}\right)=U\left(\frac{L}{2}\right)=0 \\
& -K\left(\frac{d T}{d Y}\right)_{Y=-\frac{L}{2}}=h_{1}\left[T_{1}-T\left(X,-\frac{L}{2}\right)\right], \quad-K\left(\frac{d T}{d Y}\right)_{Y=\frac{L}{2}}=h_{2}\left[T\left(X, \frac{L}{2}\right)-T_{2}\right] \\
& C_{1}\left(\frac{-L}{2}\right)=C_{1 m}, \quad C_{1}\left(\frac{L}{2}\right)=C_{1 p}, \quad C_{2}\left(\frac{-L}{2}\right)=C_{2 m}, \quad C_{2}\left(\frac{L}{2}\right)=C_{2 p}
\end{aligned}
$$

The walls of the duct exchange heat by convection with an external fluid. The coefficients of external convection at the left wall and at the right wall are respectively $h_{1}$ $h_{2}$ are taken as the. $T_{1}$ and $T_{2}$ are the reference temperatures at the left and right walls 
of the duct such that $T_{2} \geq T_{1}$. Further, it is also considered that $\frac{\partial P}{\partial X}=A$. The following dimensionless parameters are now introduced:

$$
\begin{aligned}
& u=\frac{U}{U_{0}} ; \quad \theta=\frac{T-T_{0}}{\Delta T} ; \quad y=\frac{Y}{D} ; \quad G R_{T}=\frac{g \beta_{T} \Delta T D^{3}}{v^{2}} ; \quad G R_{C 1}=\frac{g \beta_{C 1} \Delta T D^{3}}{v^{2}} \\
& G R_{C 2}=\frac{g \beta_{C 2} \Delta T D^{3}}{v^{2}} ; \quad \operatorname{Re}=\frac{U_{0} D}{v} ; \quad B r=\frac{\mu U_{0}^{2}}{K \Delta T} ; \quad \mathrm{R}_{T}=\frac{T-T_{0}}{\Delta T} ; \\
& B i_{1}=\frac{h_{1} D}{K} ; \quad B i_{2}=\frac{h_{2} D}{K} ; \quad U_{0}=\frac{-A D^{2}}{48 \mu} ; \quad \alpha_{1}=\frac{K_{1} D^{2}}{D_{m 1}} ; \quad \alpha_{2}=\frac{K_{2} D^{2}}{D_{m 2}} ; \\
& S=\frac{B i_{1} B i_{2}}{B i_{1} B i_{2}+2 B i_{1}+2 B i_{2}} ; \quad \phi_{1}=\frac{C_{1}-C_{01}}{\Delta C_{1}} ; \quad \phi_{2}=\frac{C_{2}-C_{02}}{\Delta C_{2}} ; \\
& T_{0}=\frac{T_{1}+T_{2}}{2}+S\left(\frac{1}{B i_{1}}-\frac{1}{B i_{2}}\right)\left(T_{2}-T_{1}\right) ; \quad D=2 L ; \Lambda_{1}=\frac{G R_{T}}{\operatorname{Re}} ; \quad \Lambda_{2}=\frac{G R_{C 1}}{\operatorname{Re}} ; \\
& \Lambda_{3}=\frac{G R_{C 2}}{\operatorname{Re}} ; \Delta T=T_{2}-T_{1} ; \Delta C_{1}=C_{1 p}-C_{1 m} ; \Delta C_{2}=C_{2 p}-C_{2 m} ; \\
& C_{01}=\frac{C_{1 p}+C_{1 m}}{2} ; C_{02}=\frac{C_{2 p}+C_{2 m}}{2}
\end{aligned}
$$

By employing the dimensionless quantities as in equation (8) (in which two solutal Grashof numbers and two chemical reaction parameters arise, one for each diffusing species), equations (1) to (7) can be written as follows:

$$
\begin{aligned}
& \frac{d^{2} u}{d y^{2}}+\Lambda_{1} \theta+\Lambda_{2} \phi_{1}++\Lambda_{3} \phi_{2}+48=0 \\
& \frac{d^{2} \theta}{d y^{2}}+B r\left(\frac{d u}{d y}\right)^{2}=0 \\
& \frac{d^{2} \phi_{1}}{d y^{2}}-\alpha_{1} \phi_{1}=0 \\
& \frac{d^{2} \phi_{2}}{d y^{2}}-\alpha_{2} \phi_{2}=0
\end{aligned}
$$




$$
\begin{aligned}
& u\left(-\frac{1}{4}\right)=u\left(\frac{1}{4}\right)=0 \\
& \left(\frac{d \theta}{d y}\right)_{y=-\frac{1}{4}}=B i_{1}\left(\theta\left(-\frac{1}{4}\right)+\frac{R_{T} S}{2}\left(1+\frac{4}{B i_{1}}\right)\right), \quad\left(\frac{d \theta}{d y}\right)_{y=\frac{1}{4}}=B i_{2}\left(-\theta\left(\frac{1}{4}\right)+\frac{R_{T} S}{2}\left(1+\frac{4}{B i_{2}}\right)\right) \\
& \phi_{1}\left(-\frac{1}{4}\right)=\phi_{2}\left(-\frac{1}{4}\right)=-0.5, \quad \phi_{1}\left(\frac{1}{4}\right)=\phi_{2}\left(\frac{1}{4}\right)=0.5
\end{aligned}
$$

\section{METHOD OF SOLUTION}

Equations (10) and (11) or (12), are linear second order differential equations which yield solutions by integration. The solutions emerge as:

$$
\begin{aligned}
& \phi_{1}=\frac{\operatorname{Sinh}\left(\alpha_{1} y\right)}{2 \operatorname{Sinh}\left(\alpha_{1} / 4\right)} \\
& \phi_{2}=\frac{\operatorname{Sinh}\left(\alpha_{2} y\right)}{2 \operatorname{Sinh}\left(\alpha_{2} / 4\right)}
\end{aligned}
$$

However, the exact solutions for equations (9) and (10) are not possible as they are coupled and nonlinear. Hence, recourse is made to finding approximate analytical solutions using perturbation method. Brinkman (viscous heating) number is adopted as the perturbation parameter and hence the solutions obtained can be used only for values of Brinkman number less than one. We employ the following series expansions in equations (9), (10) along with the boundary conditions as defined in equations (13) and (14):

$$
(u, \theta)=\left(u_{0}, \theta_{0}\right)+B r\left(u_{1}, \theta_{1}\right)+B r^{2}\left(u_{2}, \theta_{2}\right)+\ldots \ldots
$$

Substituting the above expansions (18) into the equations (9), (10), (13) and (14) and equating the like powers of $\mathrm{Br}$ yields the following system of ordinary linear differential equations. We neglect the terms of second and higher order as the value of Brinkman number is very much less than one $(B r<<1)$.

Zeroth order equations 


$$
\begin{aligned}
& \frac{d^{2} u_{0}}{d y^{2}}+\Lambda_{1} \theta_{0}+\Lambda_{2} \phi_{1}+\Lambda_{3} \phi_{2}+48=0 \\
& \frac{d^{2} \theta_{0}}{d y^{2}}=0 \\
& u_{0}\left(-\frac{1}{4}\right)=u_{0}\left(\frac{1}{4}\right)=0 \\
& \left(\frac{d \theta_{0}}{d y}\right)_{y=-\frac{1}{4}}=B i_{1}\left(\theta_{0}\left(-\frac{1}{4}\right)+\frac{R_{T} S}{2}\left(1+\frac{4}{B i_{1}}\right)\right),\left(\frac{d \theta_{0}}{d y}\right)_{y=-\frac{1}{4}}=B i_{2}\left(-\theta_{0}\left(\frac{1}{4}\right)+\frac{R_{T} S}{2}\left(1+\frac{4}{B i_{2}}\right)\right)
\end{aligned}
$$

First order equations

$$
\begin{aligned}
& \frac{d^{2} u_{1}}{d y^{2}}+\Lambda_{1} \theta_{1}=0 \\
& \frac{d^{2} \theta_{1}}{d y^{2}}+\left(\frac{d u_{0}}{d y}\right)^{2}=0 \\
& u_{1}\left(-\frac{1}{4}\right)=u_{1}\left(\frac{1}{4}\right)=0 \\
& \left(\frac{d \theta_{1}}{d y}\right)_{y=-\frac{1}{4}}=B i_{1}\left(\theta_{1}\right)_{y=-\frac{1}{4}},\left(\frac{d \theta_{1}}{d y}\right)_{y=\frac{1}{4}}=-B i_{2}\left(\theta_{1}\right)_{y=\frac{1}{4}}
\end{aligned}
$$

The solutions of the above equations are not presented for brevity, as they can be obtained by integrating directly.

\section{NUMERICAL SOLUTIONS}

The semi-analytical solutions obtained as above can be used only under the restriction that the Brinkman number $(B r)$ should be very much less than one. However, in many practical applications it is required to know the nature of the flow for the full spectrum of Brinkman number values i.e. low to high $(\mathrm{Br})$. To overcome the restriction on Brinkman number, the conservation equations are solved numerically using a fourth 
order Runge-Kutta method along with shooting method. Many symbolic softwares are available for this popular and efficient computational technique and the reader is referred to [36]-[40]. The solutions obtained using the numerical method are validated by comparing with perturbation solutions (for low Brinkman number). Several engineering design quantities are also of relevance in duct flows. The dimensionless Nusselt number and skin friction provide details of the heat transfer and flow characteristics at the duct walls and are defined for the left ()$_{1}$ and right ()$_{2}$ walls, respectively as follows:

$$
\begin{aligned}
& N u_{1}=\left(\frac{d \theta}{d y}\right)_{y=-\frac{1}{4}}, N u_{2}=\left(\frac{d \theta}{d y}\right)_{y=\frac{1}{4}} \\
& \tau_{1}=\left(\frac{d u}{d y}\right)_{y=-\frac{1}{4}}, \quad \tau_{2}=\left(\frac{d u}{d y}\right)_{y=\frac{1}{4}}
\end{aligned}
$$

\section{RESULTS AND DISCUSSION}

The solutions for Eqns. (10) and (11) are obtained by integrating the equations. These solutions are used to determine the solutions for the velocity and temperature fields (Eqns. (8) and (9)). In the absence of viscous dissipation $(\mathrm{Br}=0)$ the relevant system of equations is the zeroth order equations (Eqns. (17) and (18)) which are solved using boundary conditions (19) and (20). It is to be noted that many parameters arise in the boundary value problem and generally they are prescribed non-zero values, unless otherwise stated. Figs. 2-8 and Table 1 are obtained via the Runge-Kutta shooting (RKS) numerical method. Tables 2a and $\mathbf{2 b}$ include RPM (regular perturbation method) comparisons with the RKS solutions. The obtained solutions are visualized in Figs. 2 and 3. In the absence of thermal Grashof number $\left(\Lambda_{1}=0\right)$, the velocity profile is parabolic and generally symmetric about the channel centerline $(y=0)$. With increasing values of thermal Grashof number $\left(\Lambda_{1}=500,1000\right)$, reversal flow occurs in the left channel half space $(y<0)$ i.e. negative velocities are generated and this backflow is exacerbated as $\Lambda_{1}$ increases. Increasing thermal buoyancy force relative to viscous force therefore induces a damping in the flow in the left channel half space, and this has been noted in 
various other studies e.g. Gebhart et al. [9]. Conversely in the right channel half space $(y>0)$ there is a strong acceleration in the flow with increasing thermal Grashof number $\left(\Lambda_{1}\right)$ nearer the hot right wall of the duct. With non-zero thermal Grashof number therefore both deceleration and acceleration may be induced and amplified in different zones of the channel. It is also evident from Fig. 2 that in the centre of the channel $(y=0)$ the values of the velocity for all values of $\Lambda_{1}$ are in fact equal $(u=1.5)$. In the absence of thermal Grashof number, $\left(\Lambda_{1}=0\right)$ the effect of Brinkman number $(B r)$ on the temperature field for equal and unequal Biot numbers $\left(B i_{1}, B i_{2}\right)$ are shown in Figs. 3a and $3 \mathrm{~b}$ respectively. For $B r=0$, the profile for temperature is linear for equal and unequal Biot numbers as the heat transfer is only via thermal conduction. Including the effect of viscous dissipation $(B r \neq 0)$, temperature increases considerably as Brinkman number increases for both equal (Fig. 3a) and unequal (Fig. 3b) Biot numbers. It is also seen that the effect of Brinkman number is more influential near the left plate for unequal Biot numbers when compared to the equal Biot numbers. Temperature distributions clearly ascend from the left cold wall to the right hot wall for the equal Biot number case (Fig. 3a) and tend to attain a maximum closer to the right hot wall. However, for the unequal Biot number case (Fig. 3b) temperatures peak at the left wall and decay strongly towards the right wall. Furthermore, although the non-dissipative profile $(B r=0)$ is still linear for the unequal Biot number case, the gradient is much lower i.e. there is a significantly lower rate of increase in temperature from the left to the right wall in Fig. $3 \mathrm{~b}$ compared with fig. 3a. These trends are attributable to the boundary condition as given in Eq. (14). For equal Biot numbers the value of the parameter $S=0.7143$ at both the plates whereas for the unequal Biot number case, the value of $S=0.3125$ which will substantially influence the temperature field.

The effects of Brinkman number $(B r)$ on velocity $(u)$ and temperature for nonzero thermal Grashof number $\left(\Lambda_{1}>0\right)$ are depicted in Figs. 4a to 4d for equal and unequal Biot numbers. As Brinkman number increases, the velocity and temperature fields are enhanced for both equal and unequal Biot number cases. The velocity profiles 
are symmetric for equal and unequal Biot numbers (Figs 4a and 4c) although marginally higher velocities are achieved in the equal Biot number case (Fig. 4a). However, the nature of profiles for temperature field are different for equal and unequal Biot number which is associated with the boundary condition (14). Marked acceleration is induced in the flow with elevation in the Brinkman number principally in the core region of the duct away from the walls. However, a more significant boost in temperatures is generated both at the walls and across the width of the entire channel with increasing Brinkman number, since the primary effect of viscous dissipation is the conversion of kinetic energy into thermal energy in the flow. Minimum temperatures for both the equal and unequal Biot number cases are therefore attained in the absence of viscous heating $(\mathrm{Br}=0)$ indicating that neglection of this effect results in an under-prediction in the temperature magnitudes. Inclusion of viscous dissipation in mathematical models therefore produces more accurate predictions of temperature distributions for thermal duct design.

Figs. 5a to $5 \mathbf{d}$ illustrate the effects of thermal Grashof number $\left(\Lambda_{1}\right)$ on velocity $(u)$ and temperature $(\theta)$. Increasing thermal Grashof number $\left(\Lambda_{1}\right)$ clearly enhances velocities both for the equal and unequal Biot number cases, as illustrated in Figs. 5a and 5c, although substantially larger magnitudes are observed in the unequal Biot number case. Flow acceleration is also confined in both cases largely to the core zone of the duct. The velocity profile topologies are similar for both equal and unequal Biot numbers (Figs. 5a and 5c), whereas the temperature distributions deviate considerably for equal and unequal Biot numbers (Figs. 5b and 5d). The influence of $\Lambda_{1}$ on temperature field is clearly greatly amplified for unequal Biot numbers (Fig. 5d) when compared with equal Biot number (Fig. 5b). Further the enhancement of temperature at the cold wall is much greater compared to that at the hot wall for unequal Biot numbers. Hence the diffusion of heat in the regime demonstrates great sensitivity to both thermal Biot numbers in addition to the interplay between buoyancy and viscous forces (simulated via the thermal Grashof number, $\Lambda_{1}$ ). Thermal Biot number is infact a quantification of the relative importance of conduction and convection in determining the temperature history of a body being heated or cooled by convection at its surface. It therefore provides a measure of thermal resistance inside of the duct to that at the surface of the duct walls. Effectively it 
determines how quick heat transfer occurs from the surface of the body (duct walls) to the interior (duct flow). Generally flow is accelerated with the thermal Grashof number $\Lambda_{1}$ due to the elevation in thermal buoyancy forces and this in turn serves to enhance the temperatures due to the coupling effect.

Figs. 6a to 6d illustrate the effects of concentration (solutal) Grashof number $\Lambda_{2}$ (for species-1) on velocity $(u)$ and temperature $(\theta)$, again for both cases of equal and unequal Biot numbers. Increasing $\Lambda_{2}$ clearly accelerates weakly the flow in left channel half space whereas it decelerates weakly the flow in the right channel half space for the case of equal Biot numbers (Fig. 6a). However, the opposite effect is induced for unequal Biot numbers (Fig. 6c) where deceleration is generated in the left channel half space and acceleration induced in the right channel half space. Both figures generally achieve the same maximum velocity at the channel centerline. As can be seen from Fig. $6 \mathrm{~b}$ with increasing $\Lambda_{2}$, temperature decreases weakly near the left plate and increases weakly near the right plate (Fig. 6b). The marginal alterations are due to the fact that the species 1 Grashof number relates the concentration buoyancy force in species 1 to the viscous force. This has a relatively minor role in modifying temperature distributions which are more influenced by thermal Grashof number. There is also no coupling between the temperature eqn. (10) and either species diffusion eqns. (11) or (12). There is however a significant modification in temperatures near the left wall for the unequal Biot number case (Fig. 6d) and temperatures are observed to be suppressed both at the left wall and for some distance across the duct. However, at the right wall there is no tangible effect of species 1 Grashof number number $\Lambda_{2}$. Since the effect of species - 2 Grashof number $\Lambda_{3}$ is similar to that exerted by species 1 Grashof number number $\Lambda_{2}$, graphs are omitted here.

Figs. $7 \mathrm{a}$ to $7 \mathrm{~d}$ visualize the effect of first order chemical reaction parameter $\alpha_{1}$ (for species-1) and $\alpha_{2}$ (for species-2) on the distributions for species 1 concentration $\left(\phi_{1}\right)$ and species 2 concentration $\left(\phi_{2}\right)$, for equal and unequal Biot numbers. All the graphs from $7 \mathrm{a}$ to $7 \mathrm{~d}$ clearly indicate that as the strength of the chemical reaction 
increases i.e. as $\alpha_{1}$ and $\alpha_{2}$ increase, the respective concentration of each species is enhanced in the left half space whereas it is decreased in the right half space. This trend applies to both cases of equal (Fig. 7a,c) and unequal (Fig. 7b,d) Biot numbers. Evidently there is a re-distribution in species 1 and 2 with stronger chemical reaction which while constructive in the zone near the left well tends to be destructive near the right wall. The effect of $\alpha_{1}$ and $\alpha_{2}$ on the velocity and temperature fields are trivial and hence not presented. It is also noteworthy that in the absence of chemical reactions for both species $\left(\alpha_{1}=\alpha_{2}=0\right)$, the concentrations assume a linear profile from the left wall to the right wall. Overall however the inclusion of chemical reaction terms in the model shows that different species diffusion characteristics are captured which would be missed in the absence of chemical reactions.

The results drawn from Figs. 2 to 7 are for asymmetric wall heating conditions $\left(R_{T}=1\right)$. To understand the flow structure (velocity distribution, $u$ ) and temperature distributions $(\theta)$ for symmetric wall heating conditions $\left(R_{T}=0\right)$, graphs are displayed in Figs. 8a to 8d again for both cases of equal and unequal Biot numbers. The effect of Brinkman number is again to accelerate the flow and similar velocity profiles are produced for both symmetric (Fig. 8a) and asymmetric (Fig. 8c) wall heating conditions, although higher velocities are observed in the equal Biot number case (Fig. 8a). The temperature distribution for equal Biot numbers (Fig. 8b) are symmetric profiles whereas for unequal Biot numbers (Fig. 8d) they assume decay profiles from the left wall to the right wall. Generally, the effect of Biot numbers is more impactful at the left wall compared to the right wall and in this regard the behavior is similar to that observed for asymmetric wall heating conditions).

To study thermofluid characteristics at the walls of the duct, skin friction and Nusselt number are evaluated for all the governing parameters for equal and unequal Biot numbers and presented in Table-1. To summarize, for equal Biot numbers, skin friction at the left wall $\tau_{1}$ increases with thermal Grashof number $\Lambda_{1}$, Brinkman number $\mathrm{Br}$, species- 1 chemical reaction parameter $\alpha_{1}$ and species- 2 chemical reaction parameter $\alpha_{2}$ 
whereas it decreases with both species - $1 \Lambda_{2}$, and species - 2 concentration Grashof numbers $\Lambda_{3}$. The skin friction at the right wall $\tau_{2}$ decreases with all three Grashof numbers $\left(\Lambda_{1}, \Lambda_{2}, \Lambda_{3}\right)$ and $B r$ whereas it increases with $\alpha_{1}$ and $\alpha_{2}$. The Nusselt number at the left wall $N u_{1}$ increases with $\Lambda_{1}, B r, \alpha_{1}$ and $\alpha_{2}$ whereas it decreases with $\Lambda_{2}, \Lambda_{3}$. The Nusselt number $N u_{2}$ decreases with $\Lambda_{1}, \Lambda_{2}, \Lambda_{3}, B r$ and increases with $\alpha_{1}$ and $\alpha_{2}$. The effect of governing parameters on the skin friction for unequal Biot numbers exhibits a similar nature to that for equal Biot numbers. The effect of governing parameters on the Nusselt number $N u_{1}$ at the left wall for unequal Biot numbers also shows a similar effect as with the equal Biot number case. The Nusselt number $\mathrm{Nu}_{2}$ decreases for all the governing parameters at the right wall for unequal Biot numbers.

The graphs and tables shown above (Figs. 2-8 and Table 1) are the values extracted from Runge-Kutta-Shooting (RKS) numerical computations. To validate these solutions, analytical solutions are obtained using a regular perturbation method for velocity, temperature, species-1 concentration and species- 2 concentration i.e. $u, \theta, \phi_{1}$ and $\phi_{2}$. The comparison of solutions are depicted in Tables $\mathbf{2 a}$ and $\mathbf{2 b}$ again for both equal and unequal Biot numbers respectively. Inspection of these tables shows that the analytical and numerical solutions are exactly equal in the absence of Brinkman number and the error between RPM analytical and RKS numerical solutions increases as the Brinkman number increases. It is also justifiable to say that the percentage of error for unequal Biot numbers is greater than that for equal Biot numbers. Furthermore the results obtained for all the governing parameters were in good agreement with Zanchini [29] in the absence of species diffusion and chemical reaction effects $\left(\alpha_{1}=\alpha_{2}=0\right)$, although these have not been plotted for conservation of space.

\section{CONCLUSIONS}

Heat and mass transfer in triple-diffusive buoyancy-driven convection flow of a viscous fluid contained in a vertical duct with viscous heating has been studied in the presence of first order chemical reactions using Robin ("third kind") boundary conditions. Two 
different diffusing components corresponding to two different species (contaminants) have been taken into consideration each with different molecular diffusivities and chemical reaction rates. The highly nonlinear and coupled equations for mass, momentum, energy and dual species conservation governing the flow have been transformed via suitable variables into a system of ordinary differential equations with complex boundary conditions. This system has been solved by a regular perturbation method (RPM) valid for small values of viscous dissipation parameter (Brinkman number) and also by a Runge-Kutta-Shooting (RKS) method valid for all values of Brinkman number. The solutions obtained numerically and analytically are found to be equal in the absence of viscous dissipation. However, the deviation is increased with progressively larger values of Brinkman number. In the absence of chemical reaction, the results coincide with the solutions of Zanchini [29]. The simulations have shown that:

(i)In the absence of viscous dissipation, large thermal Grashof numbers induce significant flow reversal at the left plate.

(ii)In the absence of thermal Grashof number, increasing viscous dissipation (higher Brinkman number) accelerates the flow for both equal and unequal Biot numbers.

(iii) In the presence of both buoyancy force and viscous dissipation, the flow is accelerated with greater thermal Grashof number for both equal and unequal Biot numbers.

(iv) Increasing second species solutal Grashof number damps the flow in the left duct half space whereas it accelerates the flow in the right duct half space and also decreases temperatures across the entire duct width.

(v) With increasing species 1 chemical reaction parameter, concentration magnitudes of species 1 are boosted in the left duct half space whereas they are suppressed in the right duct half space. A similar response is computed for the influence of species 2 reaction parameter on the concentration profile. 
(vi) Temperatures are strongly enhanced across the duct width with increasing Brinkman number and are symmetric in nature about the channel centerline for the symmetric Biot number case (equal thermal Biot numbers at the left and right walls). These profiles are morphed for the asymmetric Biot number case (equal thermal Biot numbers at the left and right walls).

(vii) Skin friction at the left wall is increased with increasing thermal Grashof number, Brinkman number and species 1 and 2 chemical reaction parameters, whereas the contrary effect is computed with increasing species 1 and species 2 concentration Grashof numbers.

(viii) Skin friction at the right wall is noticeably reduced with an increase in all three Grashof numbers and Brinkman number whereas it is enhanced with both species 1 and 2 chemical reaction parameters.

(ix) Nusselt number at the left wall is enhanced with a rise in thermal Grashof number, Brinkman number, species 1 and 2 chemical reaction parameters whereas it is suppressed with increasing species 1 and 2 concentration Grashof numbers; the opposite effect is induced on the Nusselt number at the right wall.

The present study has revealed some interesting features of triple diffusion in dissipative reactive Newtonian flows. Future studies may consider non-Newtonian fluids e.g. viscoplastic [41] or viscoelastic [42] liquids and will be explored imminently.

Conflict of Interest: The authors declare that they have no conflict of interest.

\section{REFERENCES}

[1] W.E. Langlois, Buoyancy-driven flows in crystal-growth melts, Annual Review of Fluid Mechanics, vol. 17, pp 191-215 (1985).

[2] S.P. Anjalidevi and R. Kandasamy, Effects of chemical reaction, heat and mass transfer on laminar flow along a semi infinite horizontal plate, Heat Mass Transfer, vol. 35, pp. 465-467 (1999). 
[3] R. Muthucumaraswamy, P. Chandrakala and S.A. Raj, Radiative heat and mass transfer effects on moving isothermal vertical plate in the presence of chemical reaction, Int. J. Appl. Mech. Eng., vol. 11, pp. 639-646 (2006).

[4] R. Mehmood, S. Rana, O. Anwar Bég and A. Kadir, Numerical study of chemical reaction effects in magnetohydrodynamic Oldroyd-B oblique stagnation flow with a nonFourier heat flux model, J. Brazilian Soc. Mech Sci. Eng. (2018). https://doi.org/10.1007/s40430-018-1446-4 (14 pages).

[5] H.S. Takhar, A.J. Chamkha and G. Nath, Flow and mass transfer on a stretching sheet with a magnetic field and chemically reactive species, Int. J. Eng. Sci., vol. 38, pp. 1303-1314 (2000).

[6] M. Shamshuddin, S.R. Mishra, Ali Kadir and O. Anwar Bég, Unsteady chemotribological squeezing flow of magnetized bioconvection lubricants: numerical study, J. Nanofluids, vol. 8 (2) pp. 407-419 (2019).

[7] F.S. Ibrahim, A.M. Elaiw and A.A. Bakr, Effect of the chemical reaction and radiation absorption on the unsteady MHD free convection flow past a semiinfinite vertical permeable moving plate with heat source and suction, Comm. Nonlinear Sci. Numer. Simulation, vol. 13, pp. 1056-1066 (2008).

[8] M. Shamshuddin, S.R. Mishra, O. Anwar Bég and A. Kadir, Lie symmetry analysis and numerical solutions for thermo-solutal chemically reacting radiative micropolar flow from an inclined porous surface, Heat Transfer - Asian Research (Japan) (2018). DOI: 10.1002/htj.21358 (23 pages).

[9] B. Gebhart, Y. Jaluria, R.L. Mahajan and B. Sammakia, Buoyancy-Induced Flows and Transport. New York, NY: Hemisphere, USA (1988).

[10] J.C. Umavathi and Jaweriya Sultana, Mixed convection flow of a micropolar fluid with concentration in a vertical channel in the presence of heat source or sink, Int. J. Math. Archive, vol.3, pp. 3556-3569 (2012).

[11] I-C. Liu and J. C. Umavathi, Double diffusive convection of a micropolar fluid saturated in a sparsely packed porous medium, Heat Transfer-Asian Research, vol. 42, pp. 515-529 (2013). 
[12] J.C. Umavathi and Monica B Mohite, Double diffusive convective transport in a nanofluid-saturated porous layer with cross diffusion and variation of viscosity and conductivity, Heat Transfer Asian Research, vol. 43, pp.628-652 (2014).

[13] J. C. Umavathi and Mikhail A. Sheremet, Onset of double-diffusive convection of a sparsely packed micropolar fluid in a porous medium layer saturated with a nanofluid, Microfluidic Nanofluid, vol. 21, pp. 121-128 (2017).

[14] M.A. Celia, J.S. Kindred and I. Herrera, Contaminant transport and biodegradation. A numerical model for reactive transport in porous media, Water Resources Res., vol. 25, pp. 1141-1148 (1989).

[15] B. Chen, A. Cunningham, R. Ewing, R. Peralta and E. Visser, Two-dimensional modeling of micro scale transport and biotransformation in porous media, Numer. Methods Partial Differential Equations, vol. 10, pp. 65-83 (1994).

[16] R.W. Griffiths, The influence of a third diffusing component upon the onset of convection, J. Fluid Mech. vol. 92, pp. 659-670 (1979).

[17] R.W. Griffiths, A note on the formation of salt-finger and diffusive interfaces in three-component systems, Int. J. Heat Mass Transfer, vol. 22, pp. 1687-1693 (1979).

[18] R.W. Griffiths, The transport of multiple components through thermohaline diffusive interfaces, Deep-Sea Res., vol. 26, pp. 383-397 (1979).

[19] N.Rudraiah and V.D. Vortmeyer, Influence of permeability and of a third diffusing component upon the onset of convection in a porous medium, Int. J. Heat Mass Transfer, vol. 25, pp. 457-464 (1982).

[20] D. Poulikakos, Effect of a third diffusing component on the onset of convection in a horizontal layer, Phys. Fluids, vol. 28, pp. 3172-3174 (1985).

[21]A.J. Pearlstein, R.M. Harris and G. Terrones, The onset of convective instability in a triply diffusive fluid layer, J. Fluid Mech., vol. 202, pp.443-465 (1989).

[22] Z.H. Khan, W.A. Khan and I. Pop, Triple diffusive free convection along a horizontal plate in porous media saturated by a nanofluid with convective boundary condition, Int. J. Heat Mass Transf., vol. 66, 603-612 (2013). 
[23] I.S. Shivakumara and S.B. Naveen Kumar, Linear and weakly nonlinear triple diffusive convection in a couple stress fluid layer, Int. J. Heat Mass Transf., vol. 68, 542-553 (2014).

[24] J. Prakash, R. Bala, K. Vaid and V. Kumar, On arresting the complex growth rates in rotatory triply diffusive convection, Appli. Appl. Math. Int. J., vol 11, pp. 722-734, (2016).

[25] M. Ghalambaz, F. Moattar, A. Karbassi, M.A. Sheremet and I. Pop, Triplediffusive mixed convection in a porous open cavity, Transport in Porous Media, vol. 116, pp. 473-491 (2016).

[26] P. Wibulswas, Laminar flow and heat transfer in non-circular ducts, Ph.D. Thesis, London University, UK (1966).

[27] E. Hicken, Das temperaturfeld in laminar durchstromten Kanalen Mitechteckquerschnitt bei unterschiedlicher Beheizung der Kanalwade. Warme Stoffubertragung, vol. 1, pp. 98-104 (1968).

[28] V.Javeri, Laminar heat transfer in a rectangular channel for the temperature boundary condition of the third kind, Int. J. Heat Mass Transf., vol. 10, pp.1029-1034 (1978).

[29] E. Zanchini, Effect of viscous dissipation on mixed convection in a vertical channel with boundary conditions of the third kind, Int. J. Heat Mass Transf., vol. 41, pp.3949-3959 (1998).

[30] J. C. Umavathi, J. Prathap Kumar and J. Sultana, Mixed convection flow in a vertical channel with boundary conditions of the third kind in the presence of heat source/sink, Appl. Math. Mech.-Engl. Ed., vol. 33, pp. 1015-1034 (2012).

[31] J.C. Umavathi and S.Veershetty, Non-Darcy mixed convection in a vertical porous channel with boundary conditions of third kind, Trans. Porous Media, vol. 95, pp. 111131 (2012).

[32] J. C. Umavathi, J. P. Kumar and J. Sultana, Mixed convection flow in a vertical porous channel with boundary conditions of third kind with heat source/sink, J. Porous Media, vol. 15, pp. 998-1007 (2012). 
[33] J. C. Umavathi and J. Sultana, Mixed convective flow of micropolar fluid mixture in a vertical channel with boundary conditions of third kind, J. Eng. Phys and Thermo Phys., vol. 85, pp. 895-908 (2012).

[34] J. Prathap Kumar, J.C. Umavathi, Ali J. Chamkha and Y Ramarao, Mixed convection of electrically conducting viscous fluid in a vertical channel using Robin boundary conditions, Canadian J. of Physics, vol. 93, pp. 698-710 (2015).

[35] J. Prathap Kumar, J.C. Umavathi, Ali J. Chamkha and Y. Ramarao, Mixed convective heat transfer of immiscible fluids in a vertical channel with boundary conditions of the third kind, Computational Thermal Science, vol. 9, pp. 447-465, (2017).

[36] O. Anwar Bég, M. J. Uddin, M.M. Rashidi, and N. Kavyani, Double-diffusive radiative magnetic mixed convective slip flow with Biot and Richardson number effects, J. Engineering Thermophysics, 23 (2), pp. $79-97$ (2014).

[37] M. J. Uddin, O. Anwar Bég, A. Aziz and A. I. M. Ismail, Group analysis of free convection flow of a magnetic nanofluid with chemical reaction, Math. Prob. Engineering 2015, Article ID 621503, 11 pp (2015). doi:10.1155/2015/621503.

[38] Nur Amalina Latiff, Md. Jashim Uddin, O. Anwar Bég and Ahmad Izani Md. Ismail, Unsteady forced bioconvection slip flow of a micropolar nanofluid from a stretching/ shrinking sheet, Proc. IMECHE- Part N: J. Nanoengineering and Nanosystems, 230 (4) pp. 177-187 (2016).

[39] M.J. Uddin, O. Anwar Bég and A.I. Ismail, Radiative-convective nanofluid flow past a stretching/shrinking sheet with slip effects, AIAA J. Thermophysics Heat Transfer, 29, 3, pp. 513-523 (2015).

[40] J. Prakash, E.P. Siva, D Tripathi, S. Kuharat and O. Anwar Bég, Peristaltic pumping of magnetic nanofluids with thermal radiation and temperature-dependent viscosity effects: modelling a solar magneto-biomimetic nanopump, Renewable Energy (2018). doi.org/10.1016/j.renene.2018.08.096 0960-1481

[41] B. Vasu, Atul Kumar Ray, O. Anwar Bég and Rama Subba Reddy Gorla, Magnetobioconvection flow of a Casson thin film with nanoparticles over an unsteady stretching sheet: HAM and GDQ computation, Int. J. Numerical Methods Heat Fluid Flow (2019). doi.org/10.1108/HFF-02-2019-0158. 
[42] N. Manzoor, O. Anwar Bég, K. Maqbool and S. Shaheen, Mathematical modelling of ciliary propulsion of an electrically-conducting Johnson-Segalman physiological fluid in a channel with slip, Computer Methods in Biomechanics and Biomedical Engineering (2019). https://doi.org/10.1080/10255842.2019.1582033

\section{FIGURES}

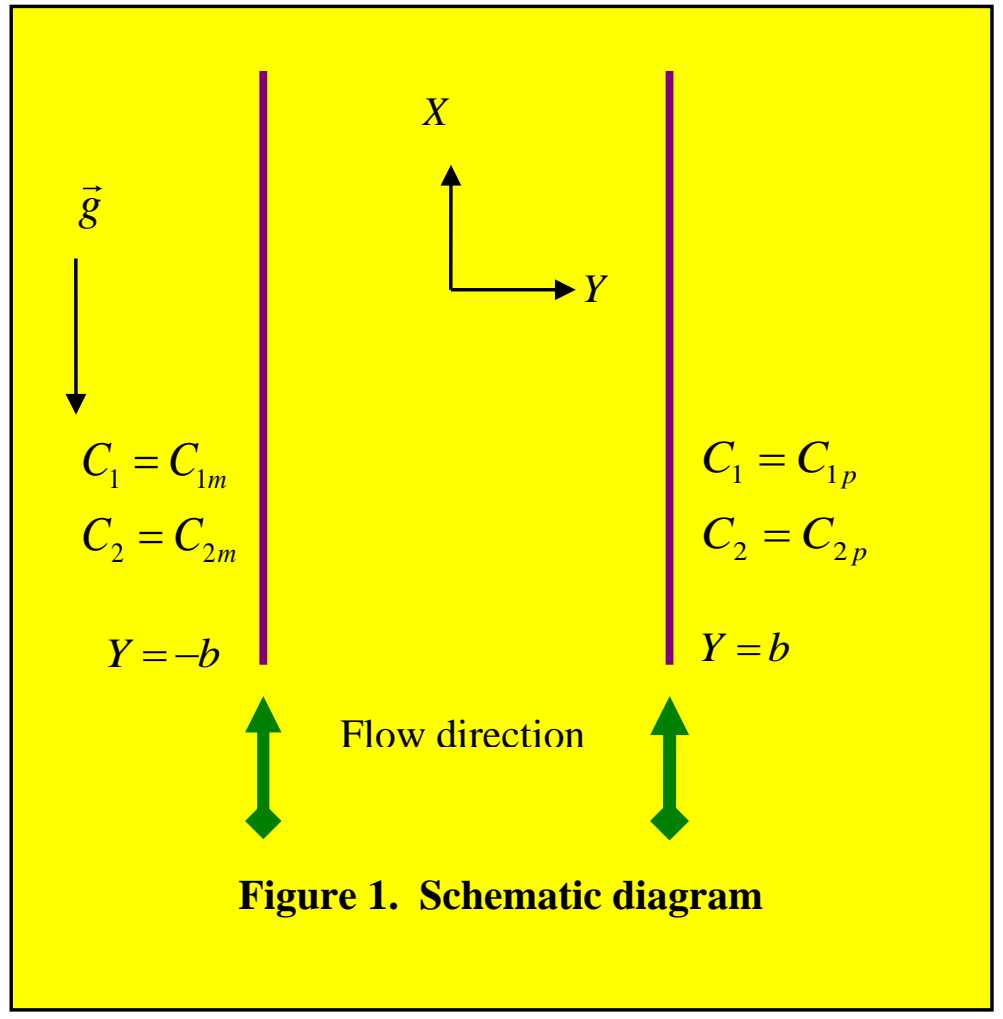




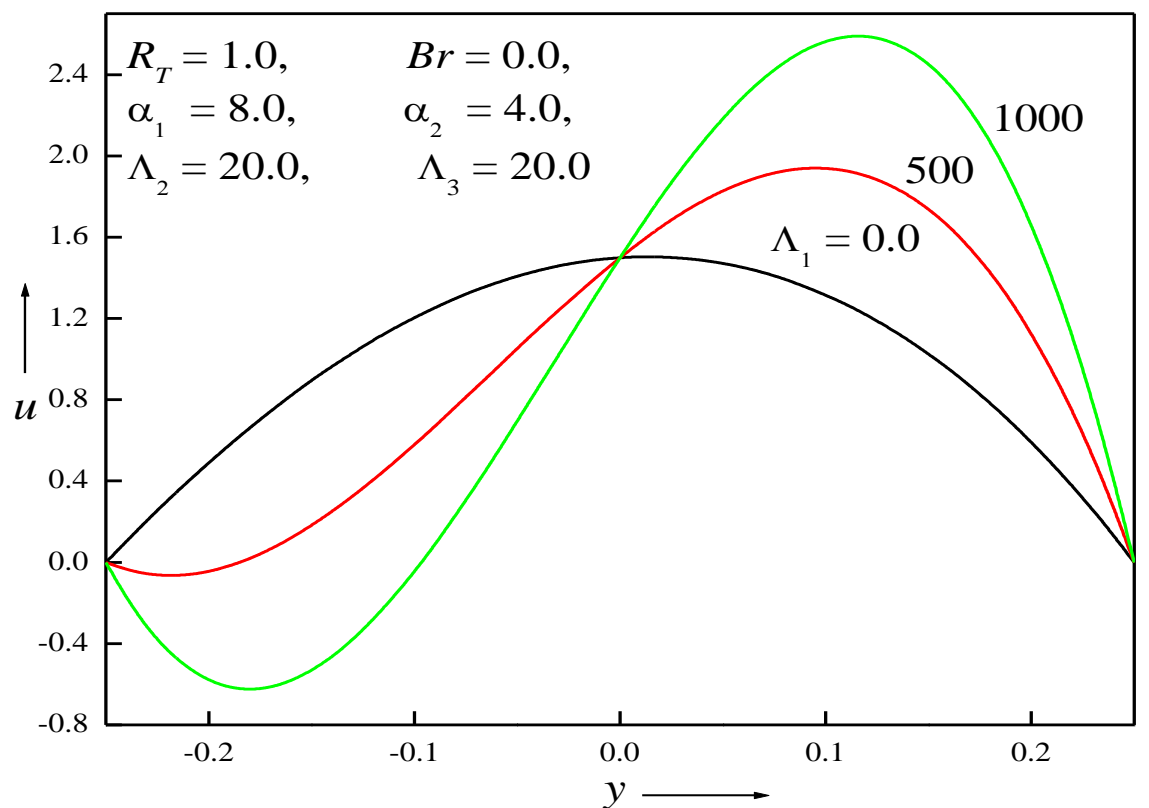

Fig. 2 Plots of $u$ versus $\Lambda_{1}$ for $B i_{1}=10, B i_{2}=10$.

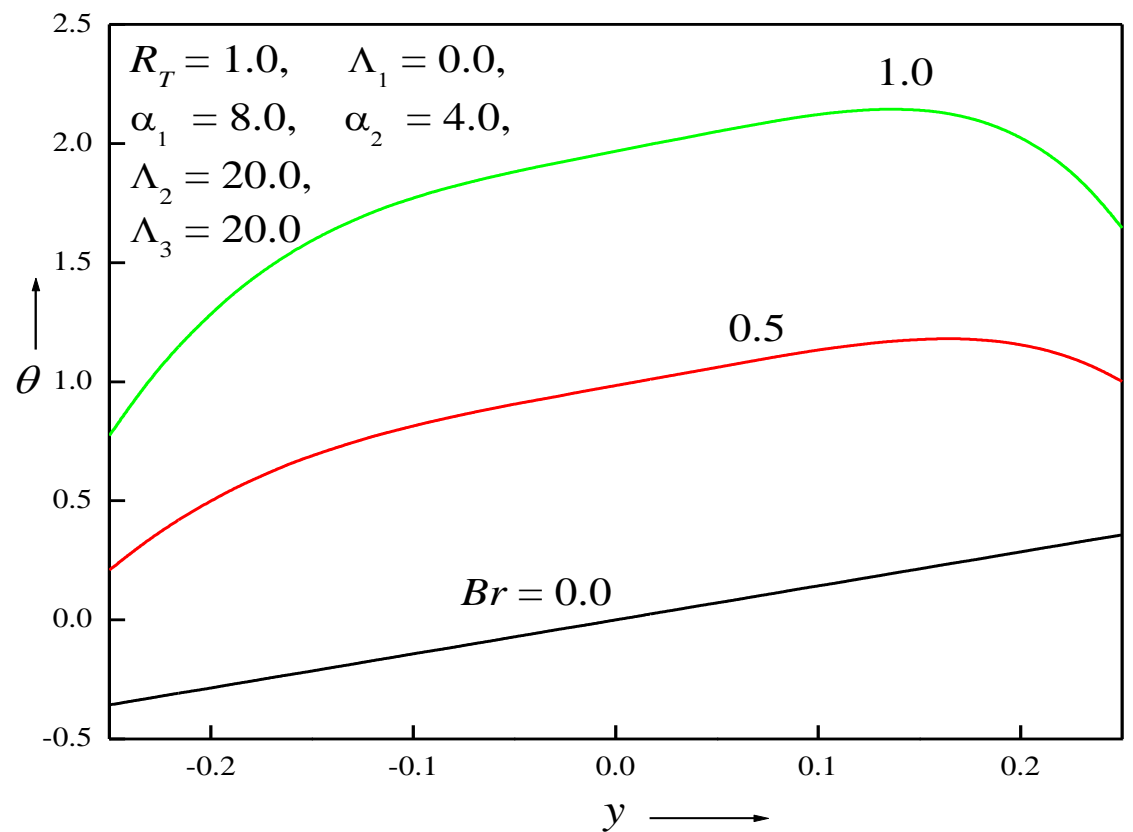

Fig. 3a Plots of $\theta$ versus $B r$ for $B i_{1}=10$ and $B i_{2}=10$ 


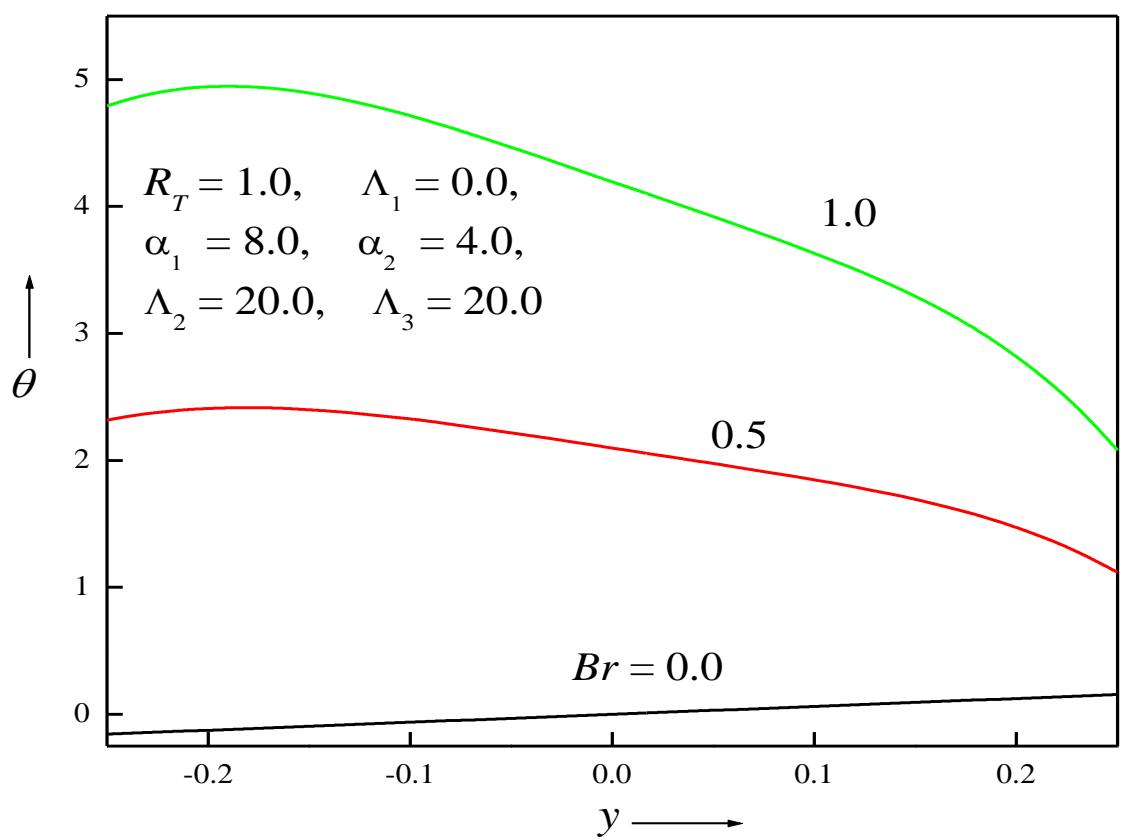

Fig. $3 b$ Plots of $\theta$ versus $B r$ for $B i_{1}=1$ and $B i_{2}=10$

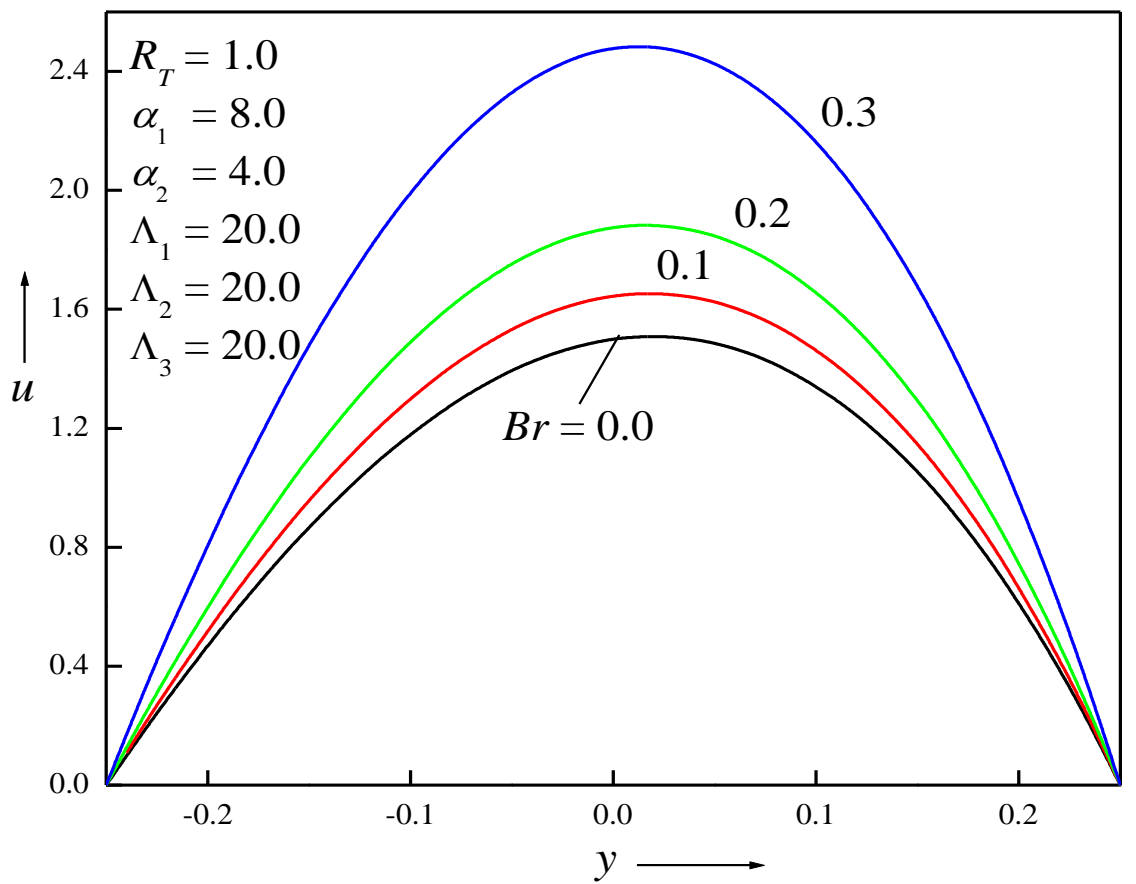

Fig. 4a Plots of $u$ versus $B r$ for $B i_{1}=10$ and $B i_{2}=10$ 


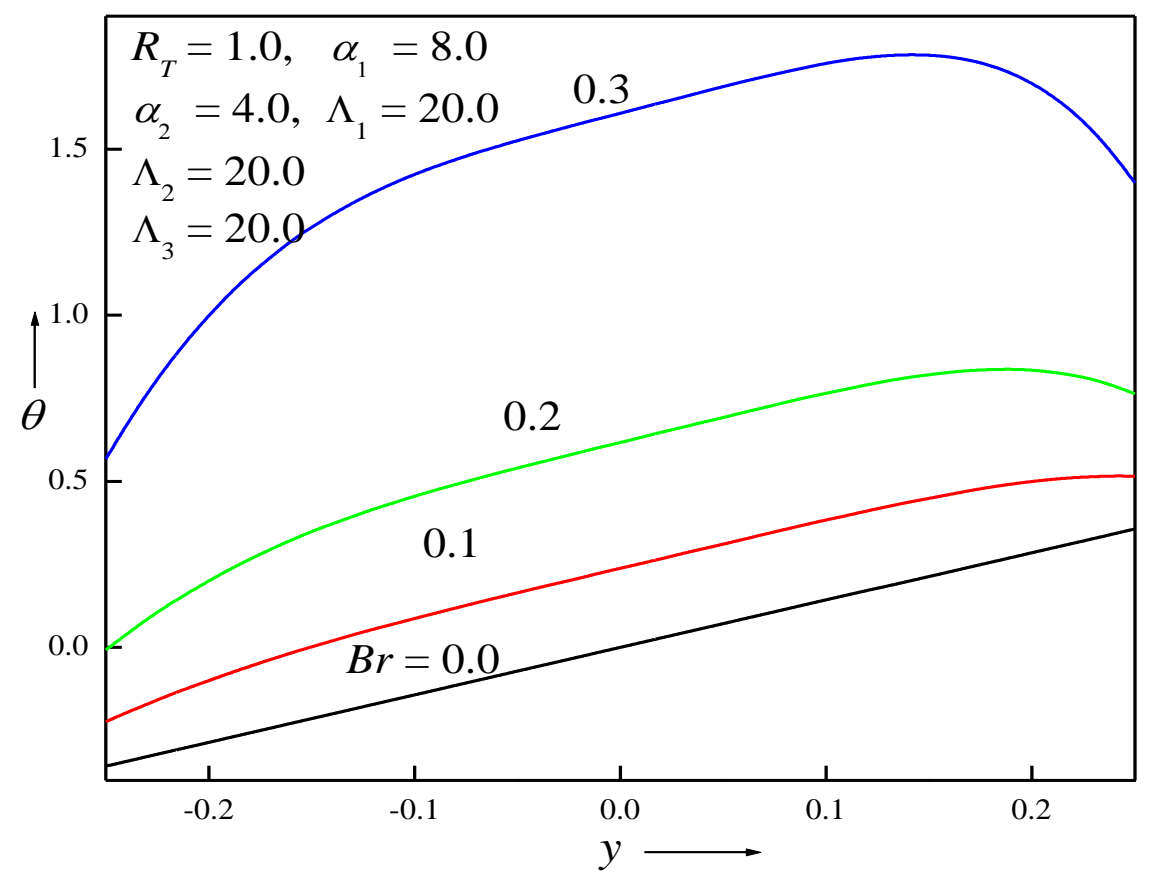

Fig. 4b Plots of $\theta$ versus $B r$ for $B i_{1}=10$ and $B i_{2}=10$

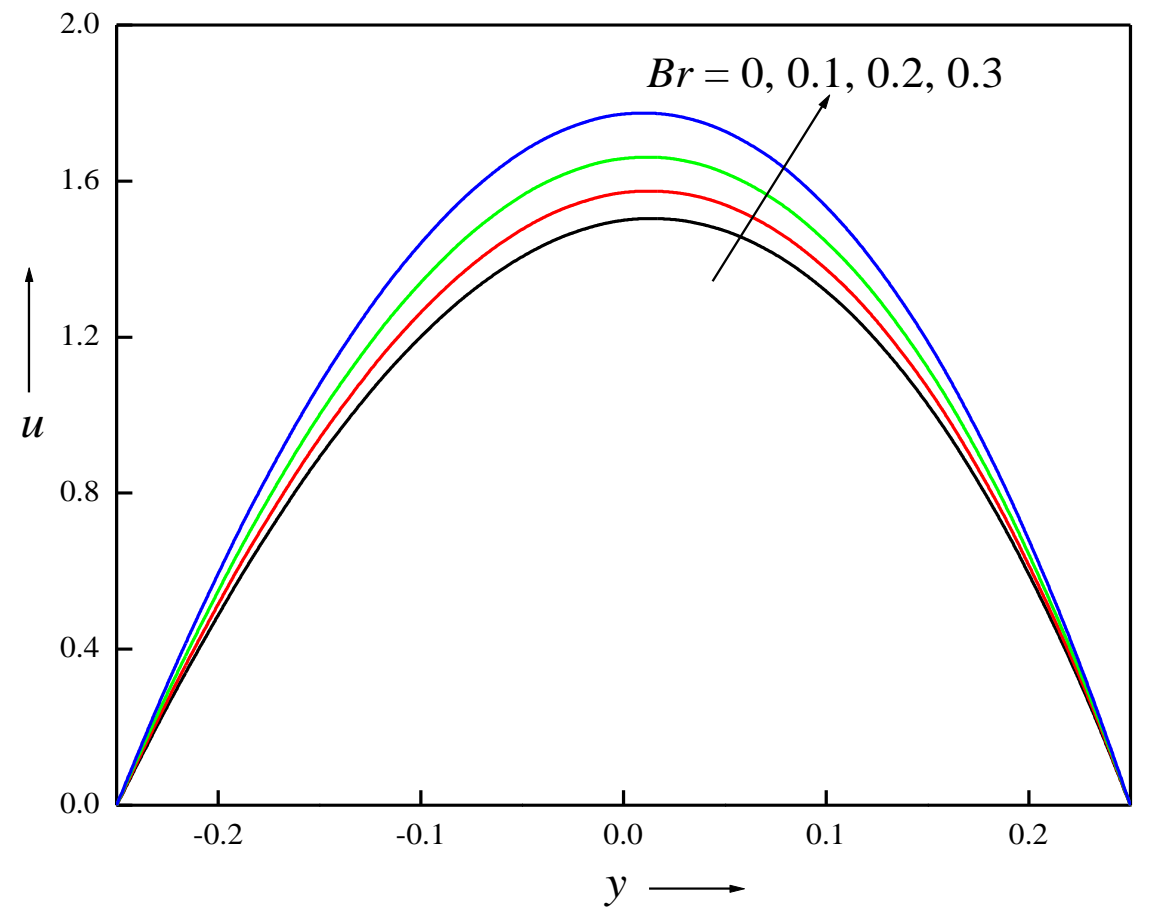

Fig. $4 \mathrm{c}$ Plots of $u$ versus $B r$ for $B i_{1}=1$ and $B i_{2}=10$ 


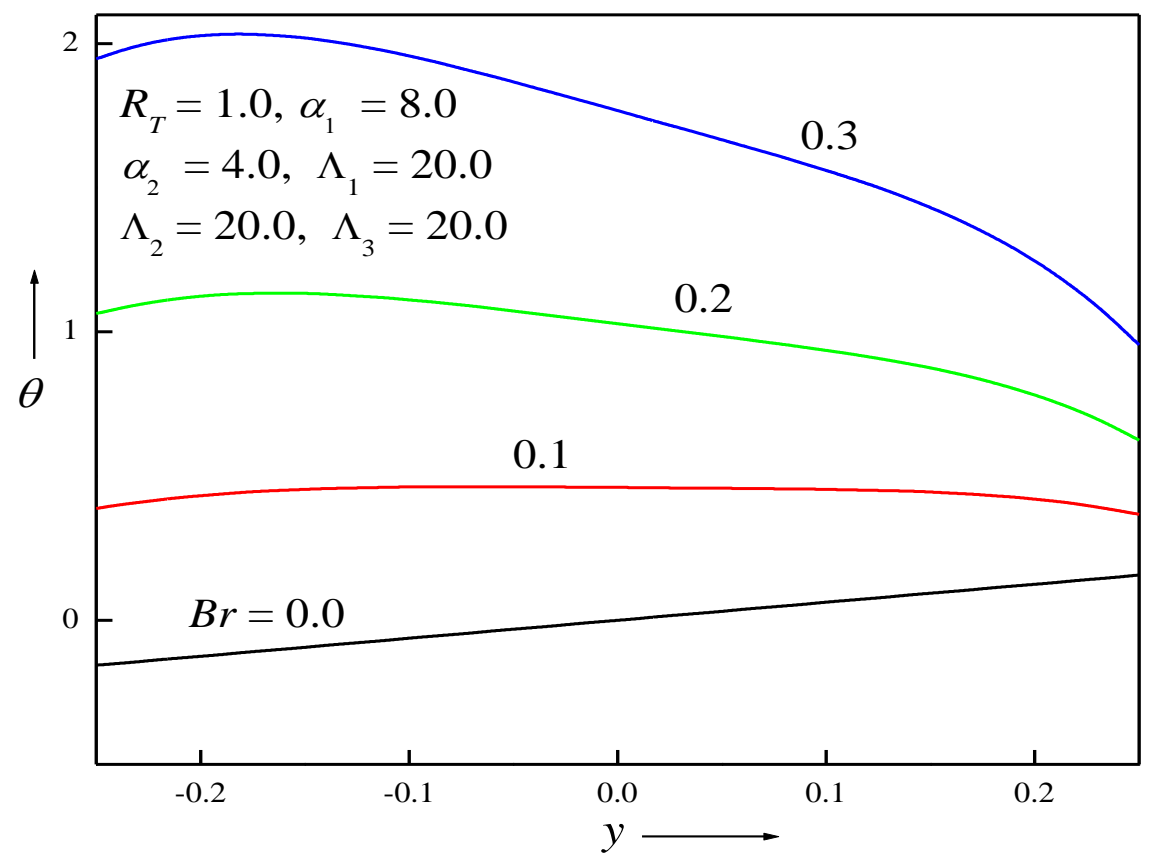

Fig. 4d Plots of $\theta$ versus $B r$ for $B i_{1}=1$ and $B i_{2}=10$

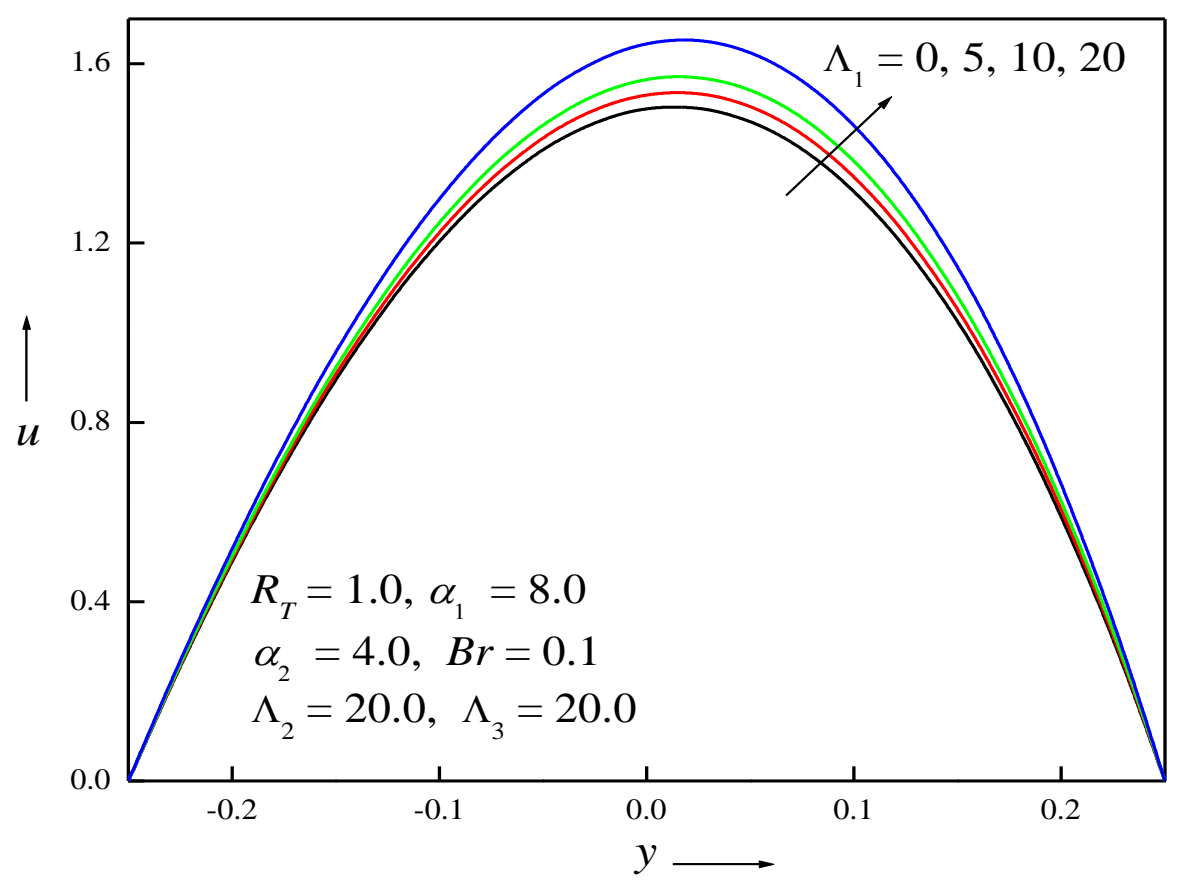

Fig. 5a Plots of $u$ versus $\Lambda_{1}$ for $B i_{1}=10, B i_{2}=10$ 


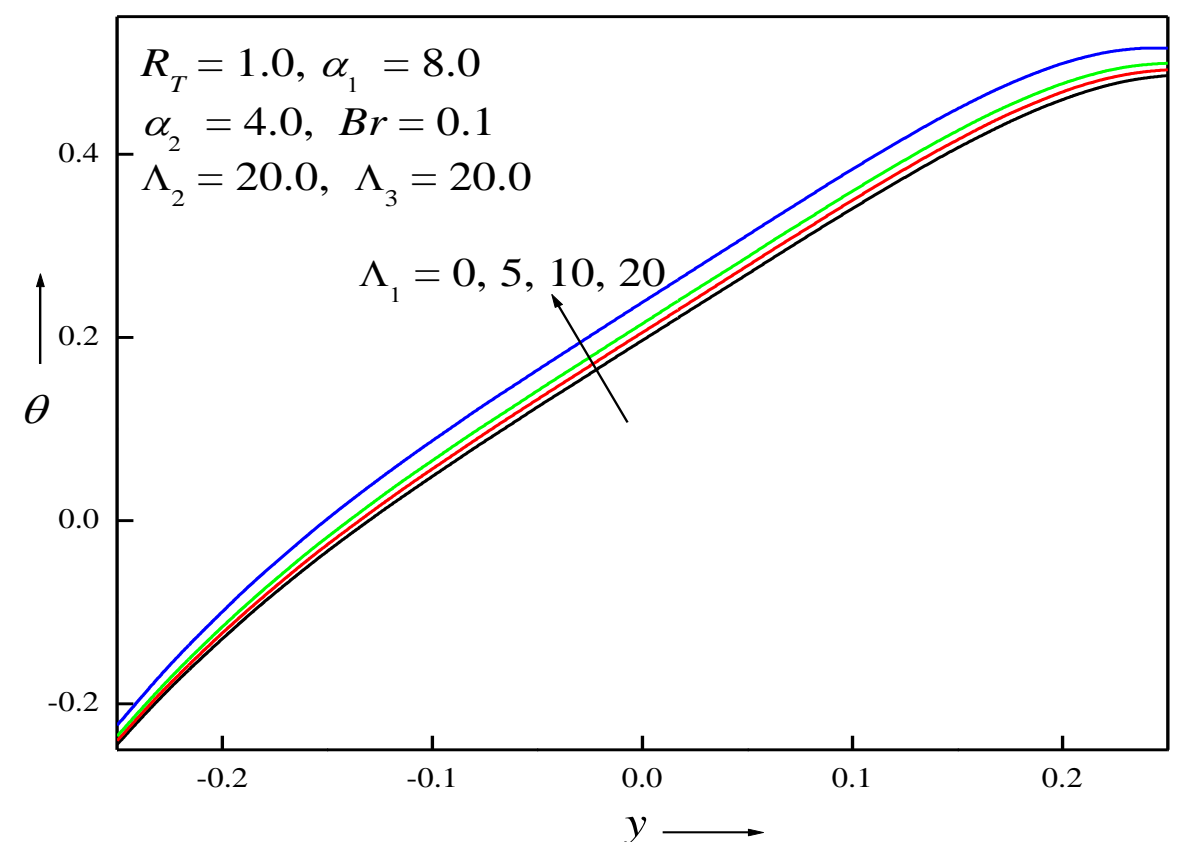

Fig. 5b Plots of $\theta$ versus $\Lambda_{1}$ for $B i_{1}=10, B i_{2}=10$

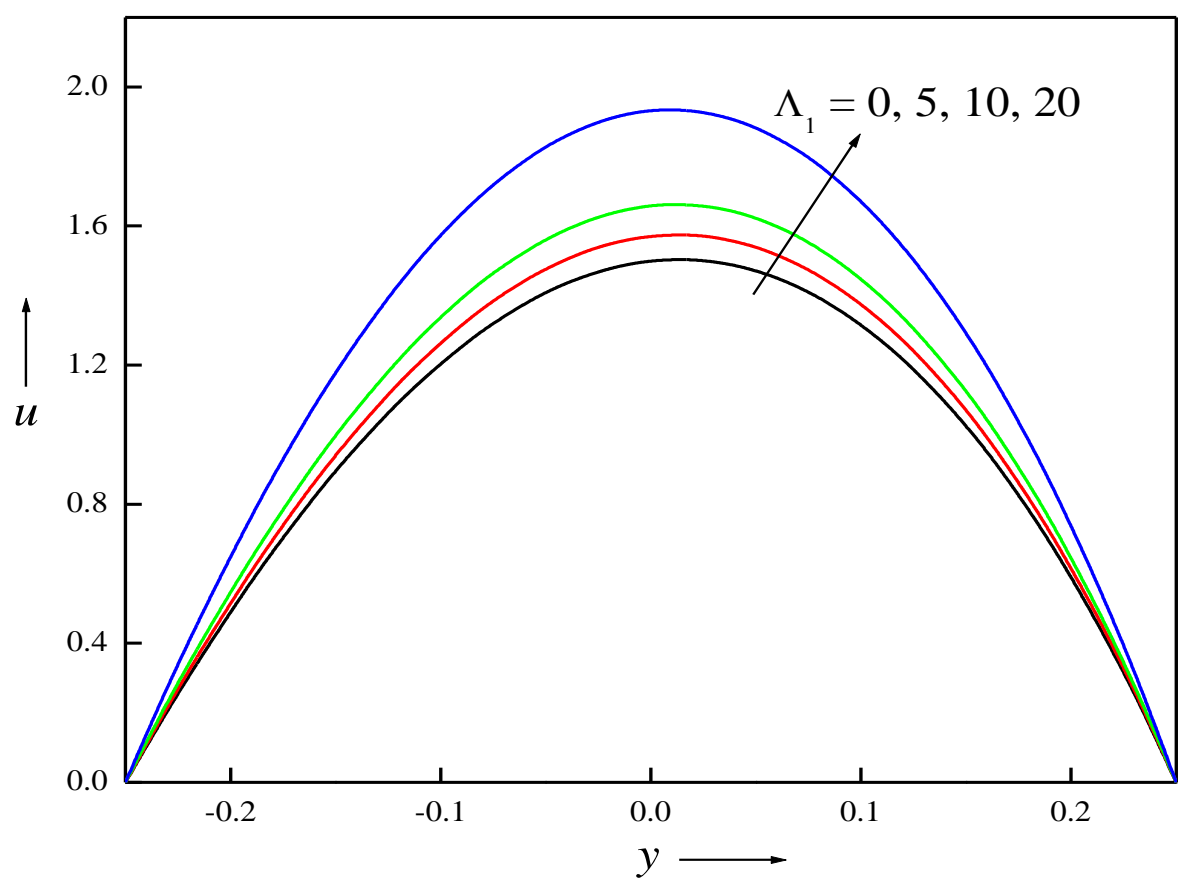

Fig. 5c Plots of $u$ versus $\Lambda_{1}$ for $B i_{1}=1, B i_{2}=10$ 


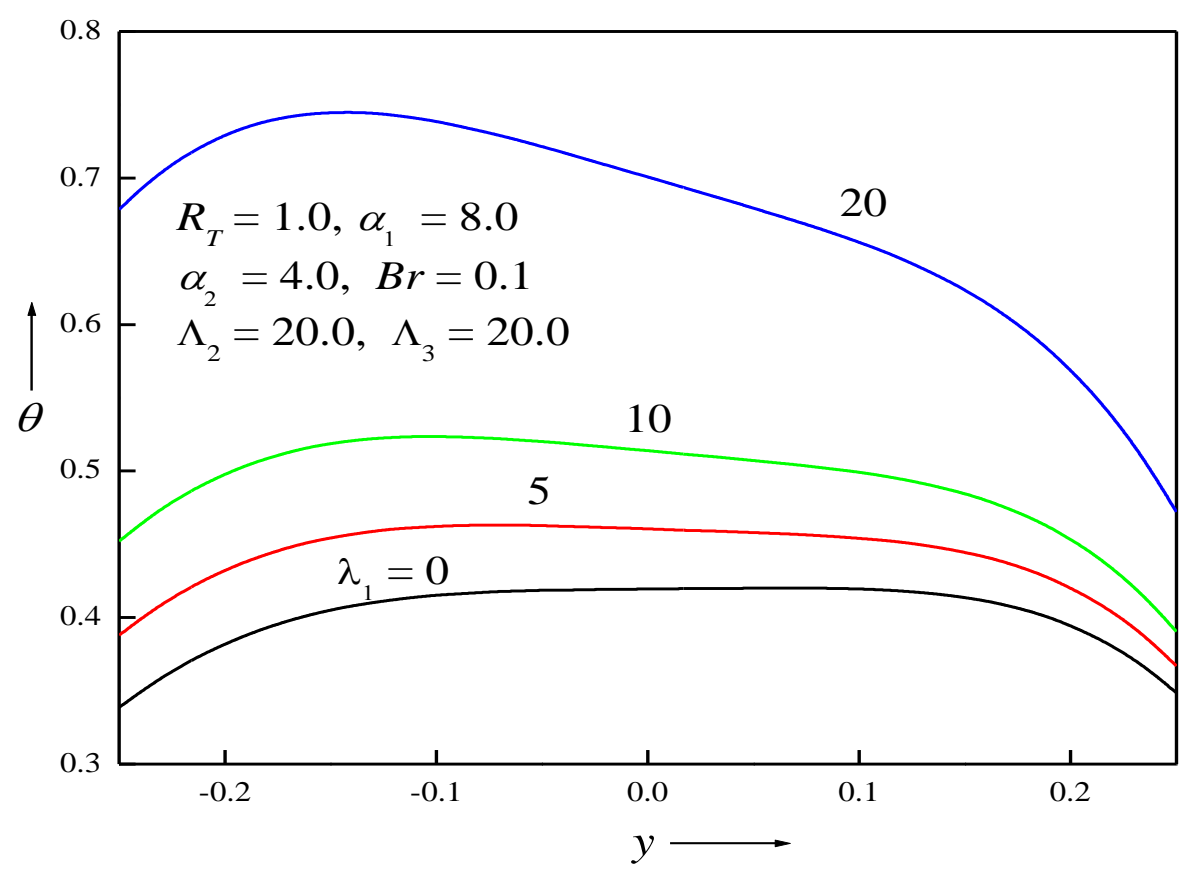

Fig. 5d Plots of $\theta$ versus $\Lambda_{1}$ for $B i_{1}=1, B i_{2}=10$

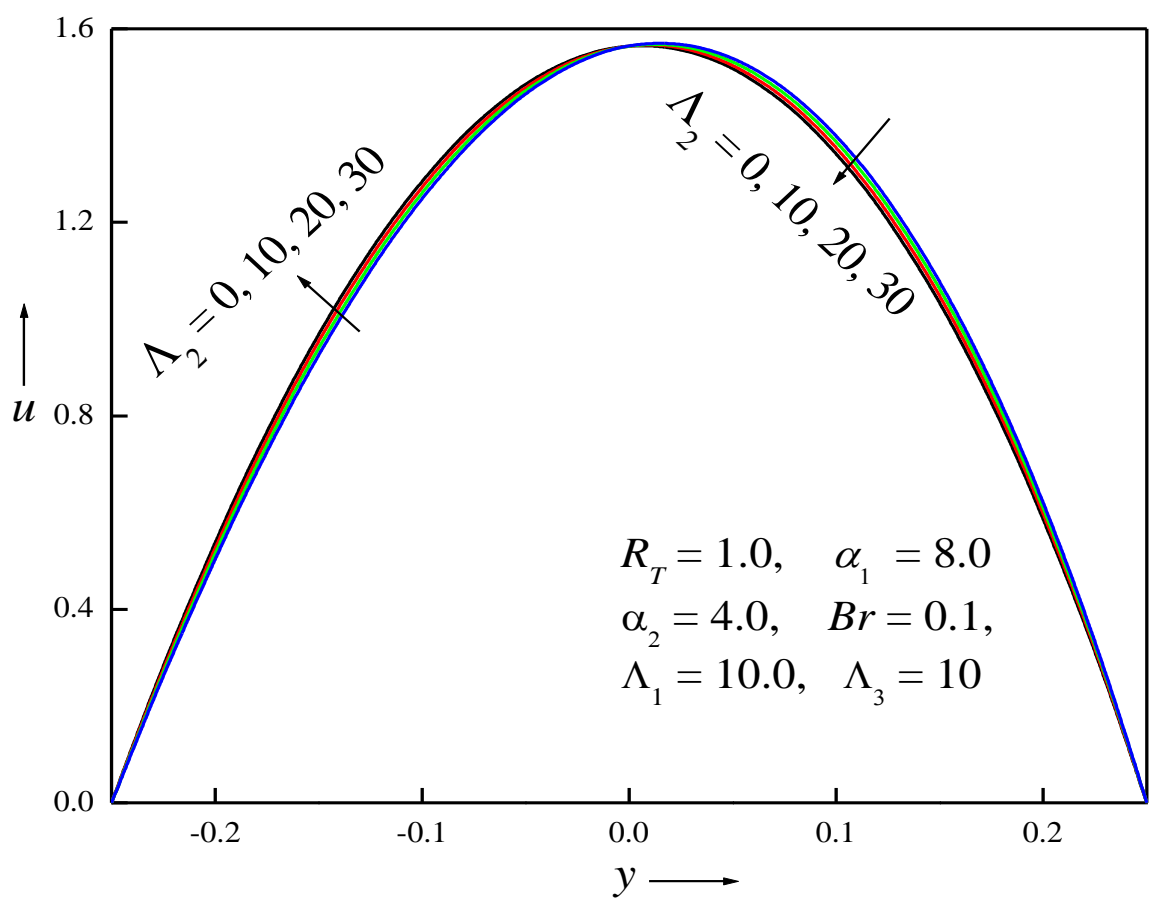

Fig. 6a Plots of $u$ versus $\Lambda_{2}$ for $B i_{1}=10$ and $B i_{2}=10$ 


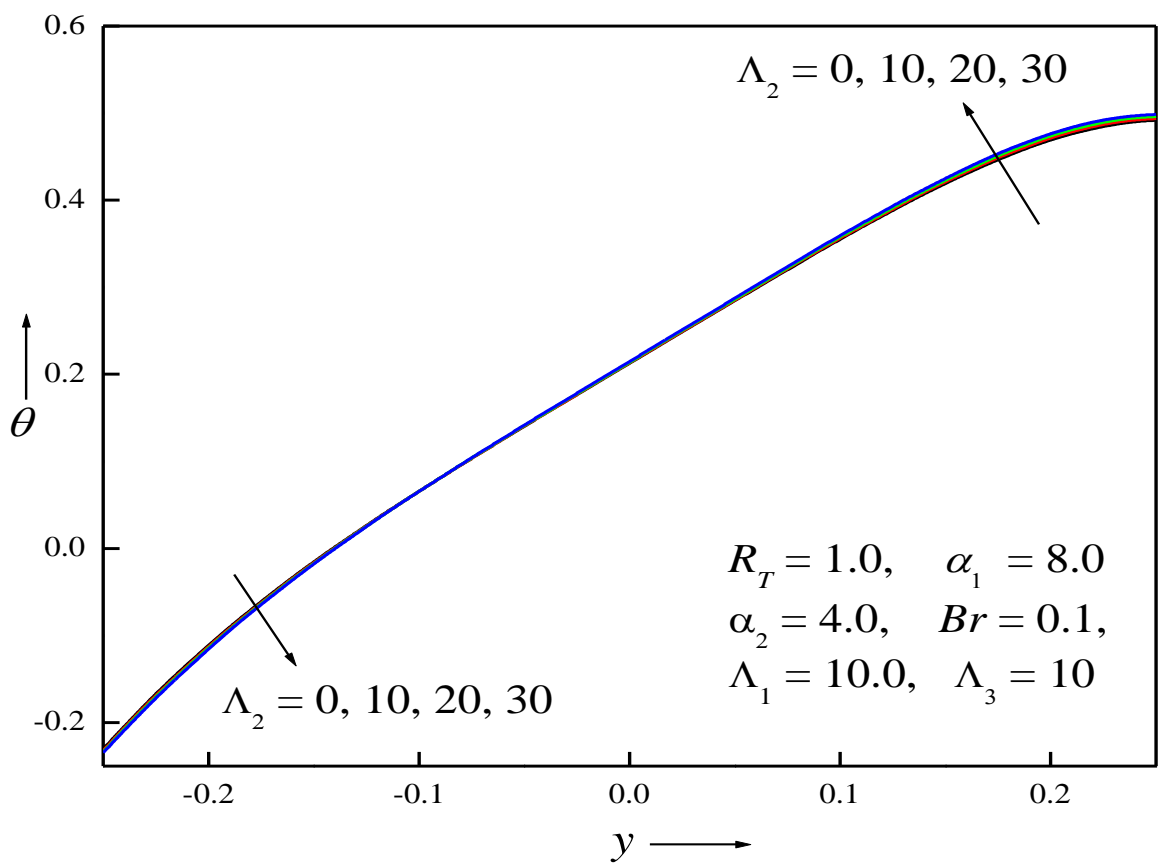

Fig. $6 \mathrm{~b}$ Plots of $\theta$ versus $\Lambda_{2}$ for $B i_{1}=10, B i_{2}=10$

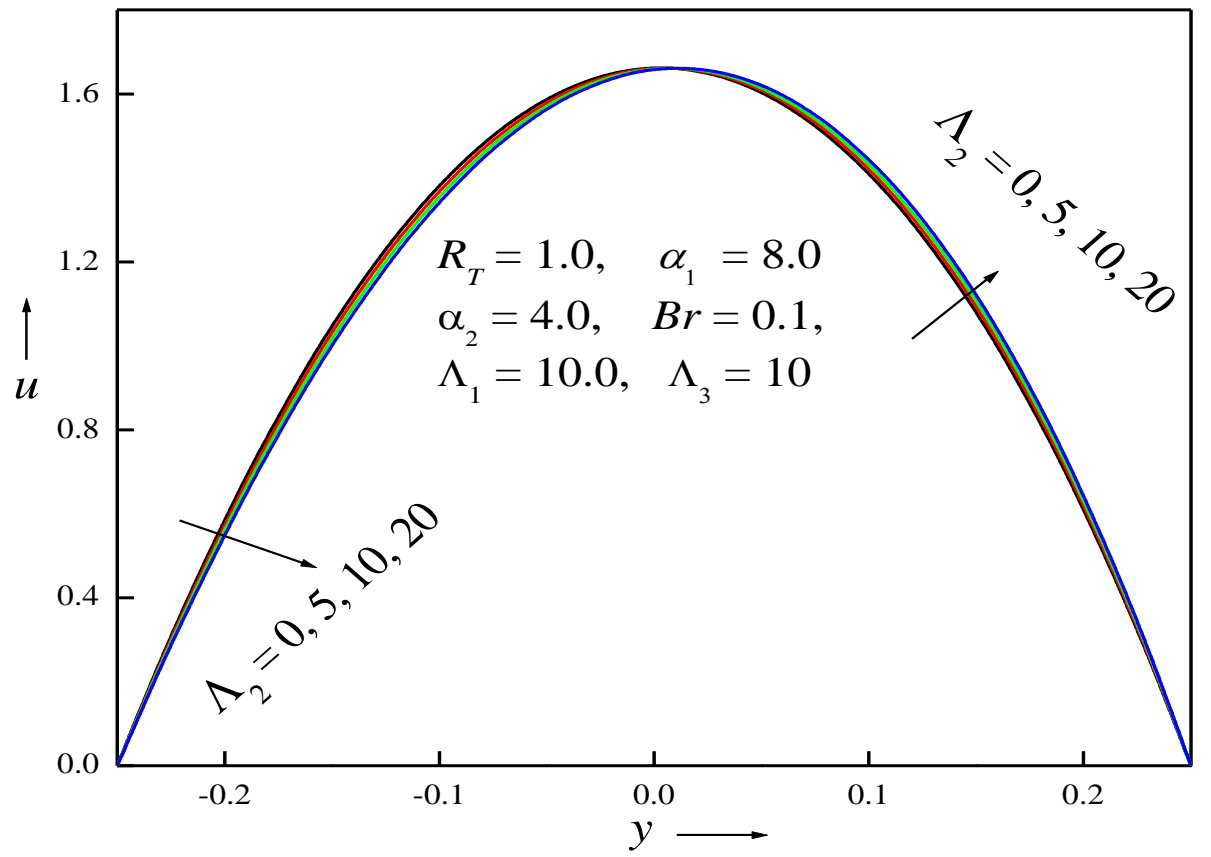

Fig. 6c Plots of $u$ versus $\Lambda_{2}$ for $B i_{1}=1, B i_{2}=10$ 


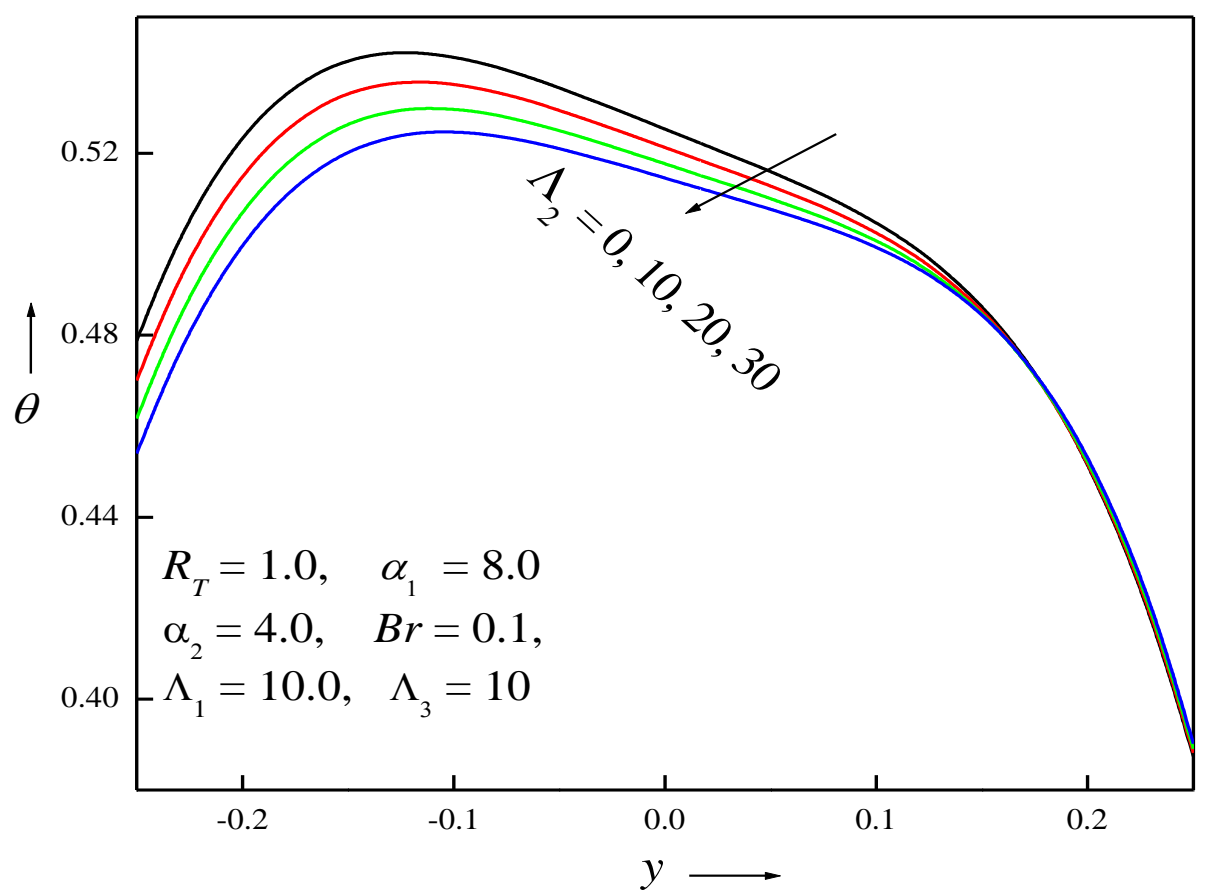

Fig. 6d Plots of $\theta$ versus $\Lambda_{2}$ for $B i_{1}=1, B i_{2}=10$

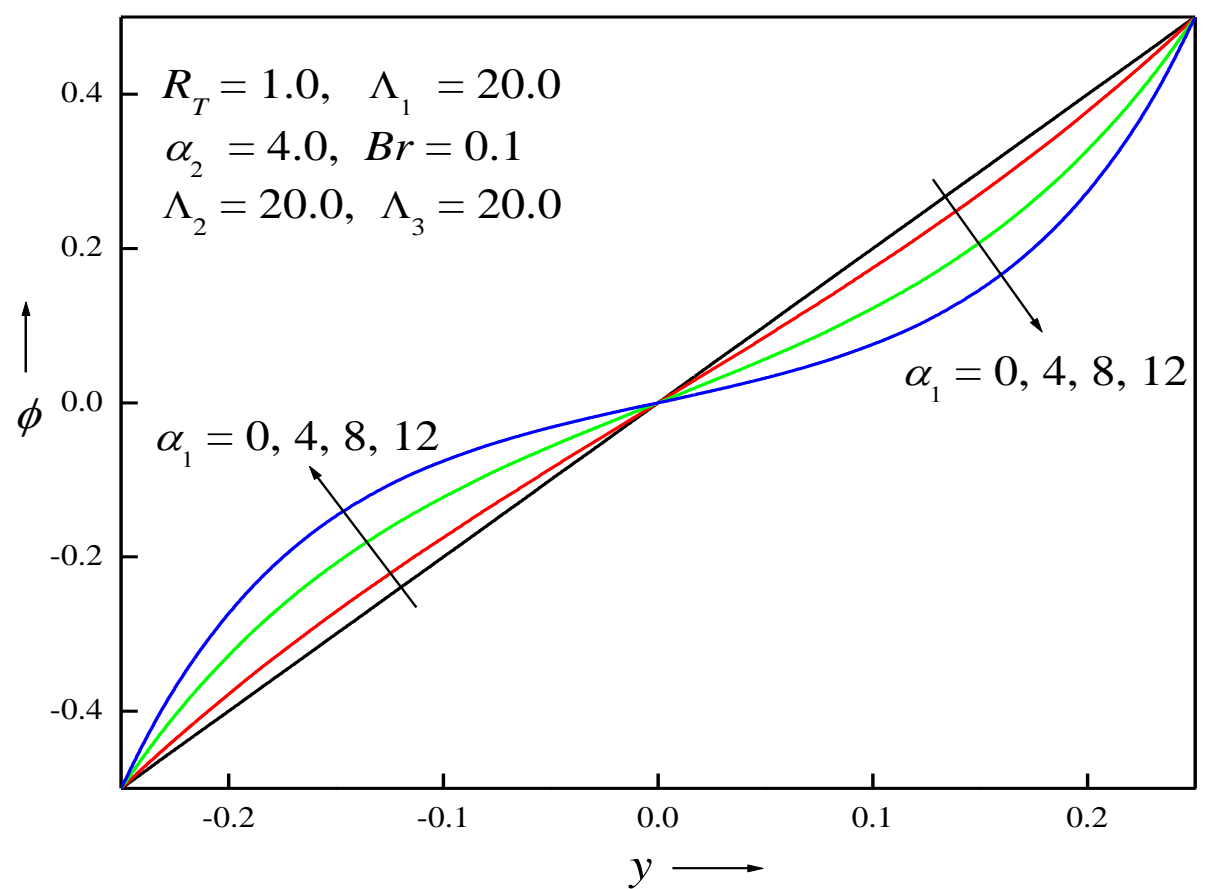

Fig. 7a Plots of $\phi$ versus $\alpha_{1}$ for $B i_{1}=10, B i_{2}=10$ 


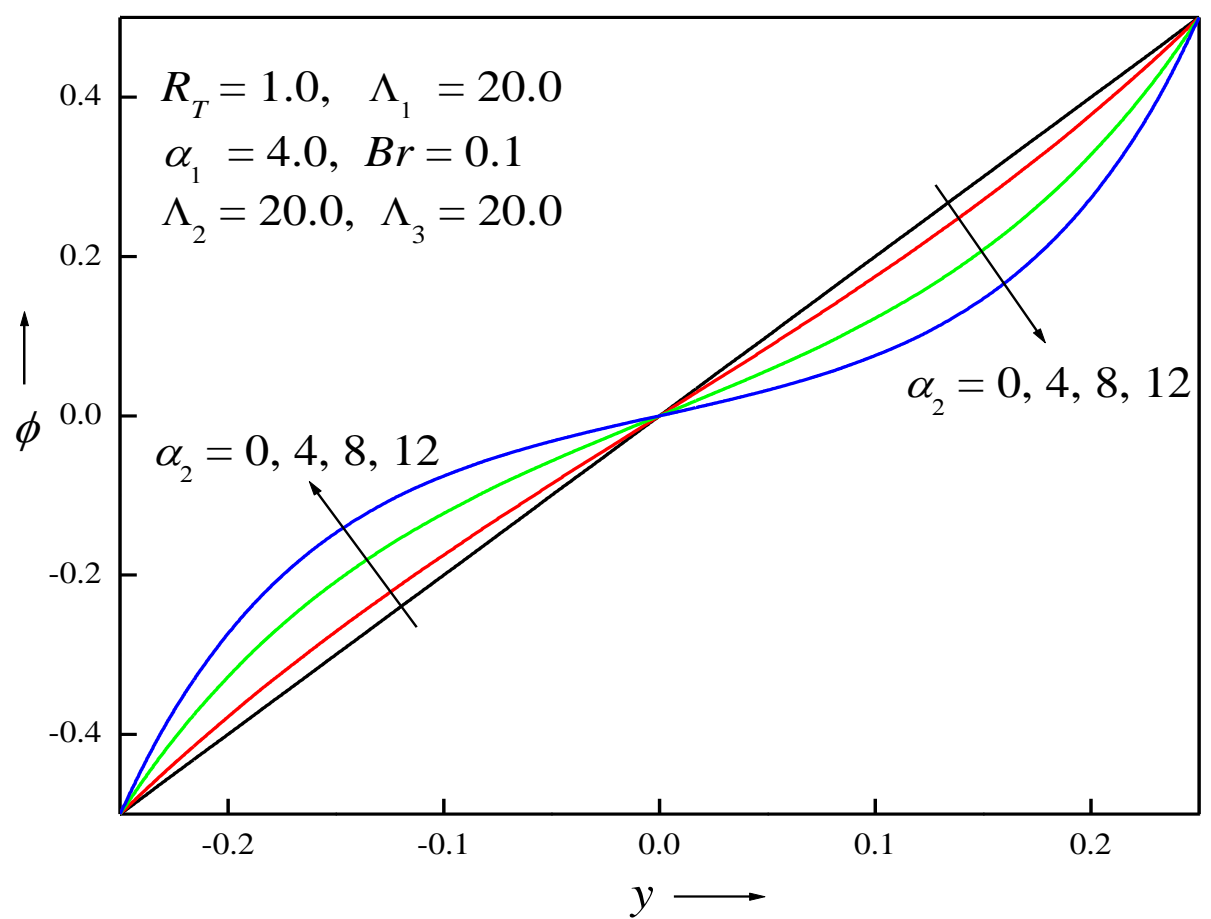

Fig. 7b Plots of $\phi$ versus $\alpha_{2}$ for $B i_{1}=10, B i_{2}=10$

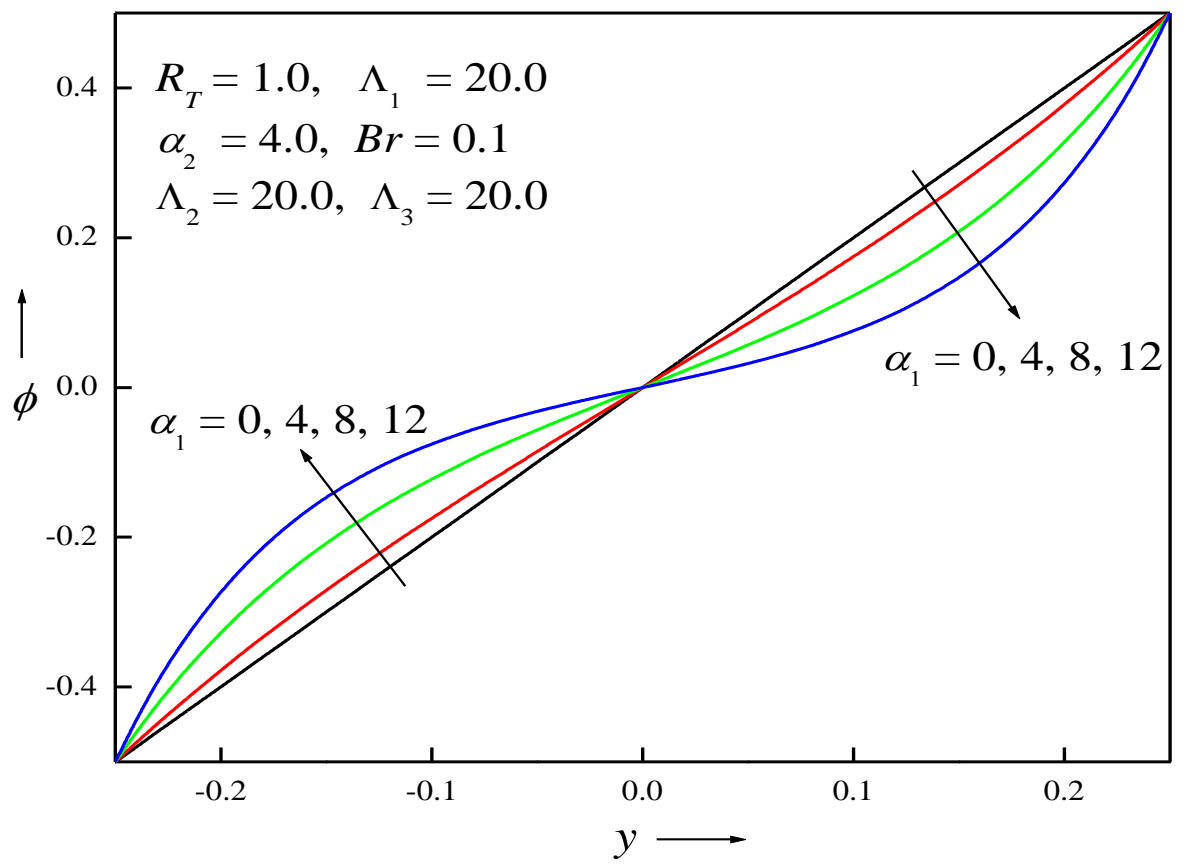

Fig. 7c Plots of $\phi$ versus $\alpha_{1}$ for $B i_{1}=1, B i_{2}=10$ 


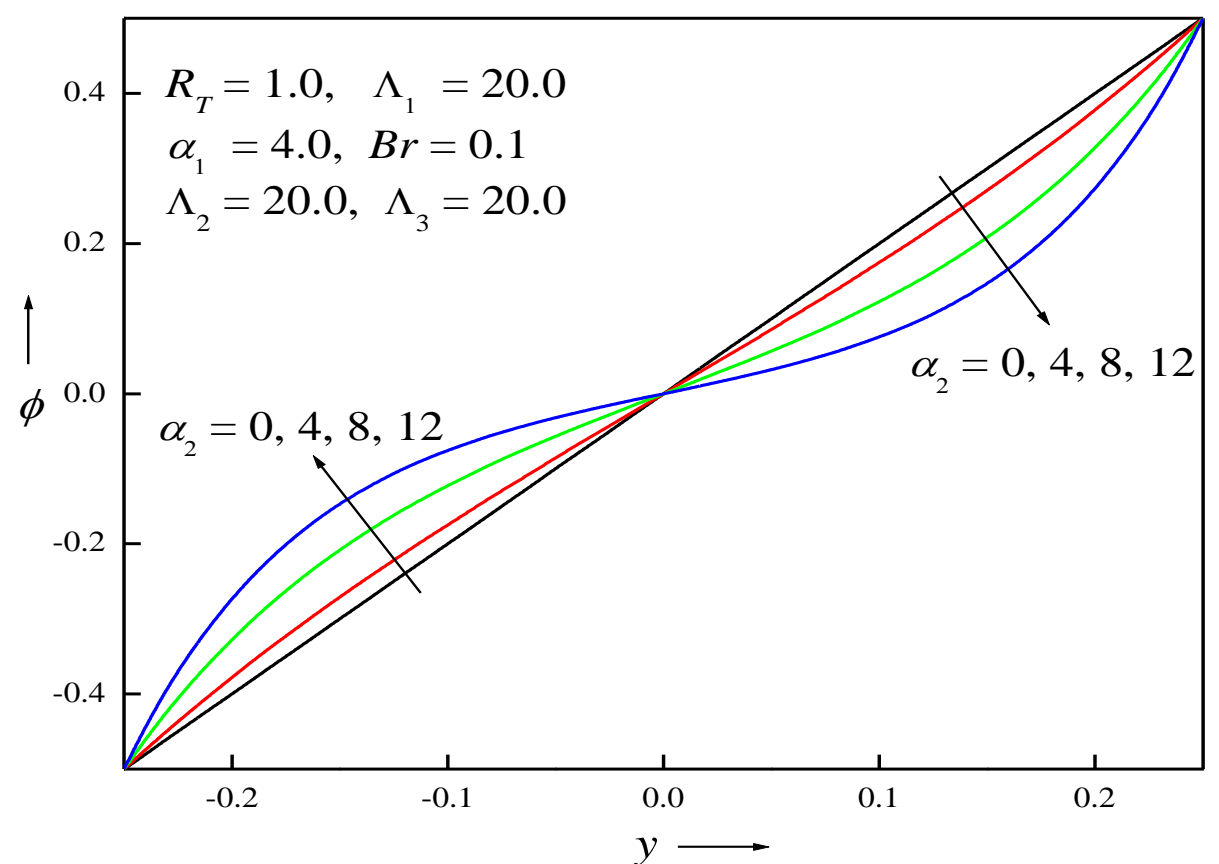

Fig. 7d Plots of $\phi$ versus $\alpha_{1}$ for $B i_{1}=1, B i_{2}=10$

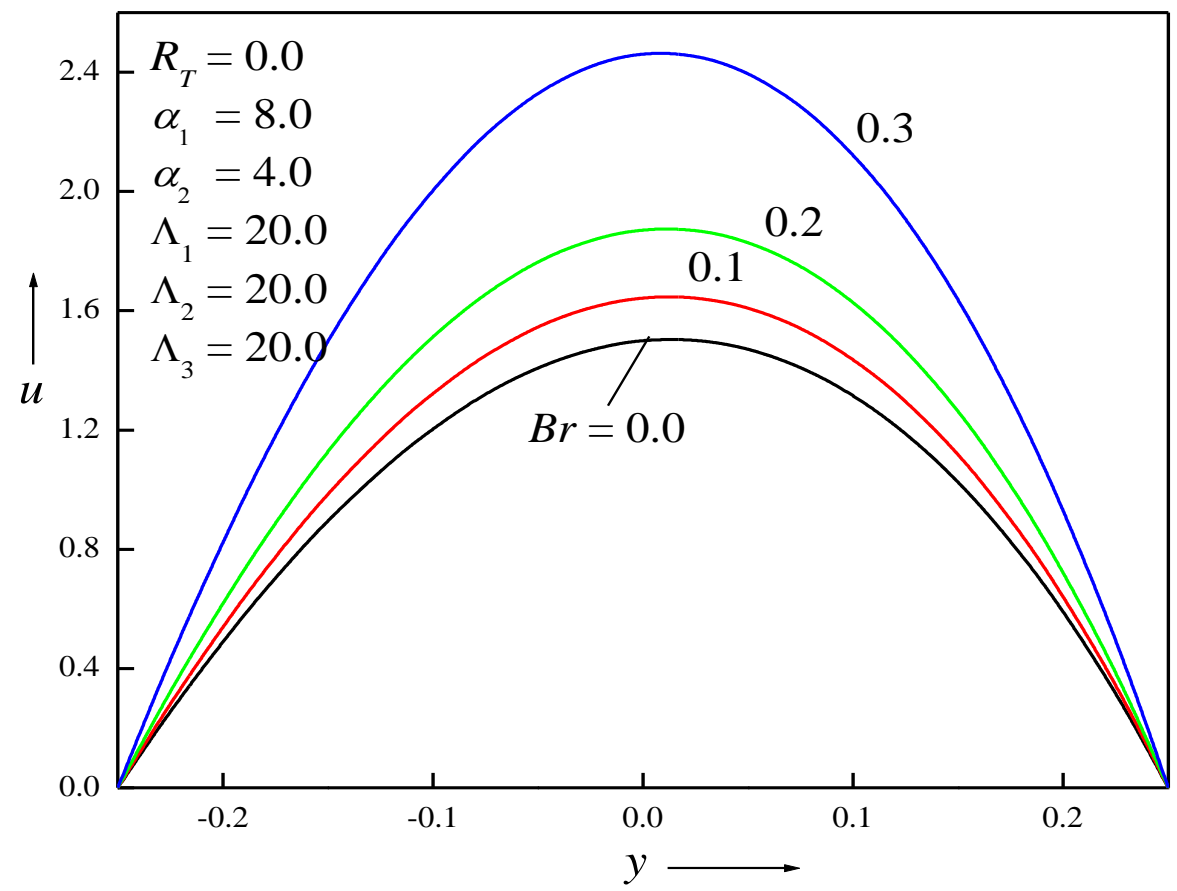

Fig. 8a Plots of $u$ versus $B r$ for $B i_{1}=10$ and $B i_{2}=10$ 


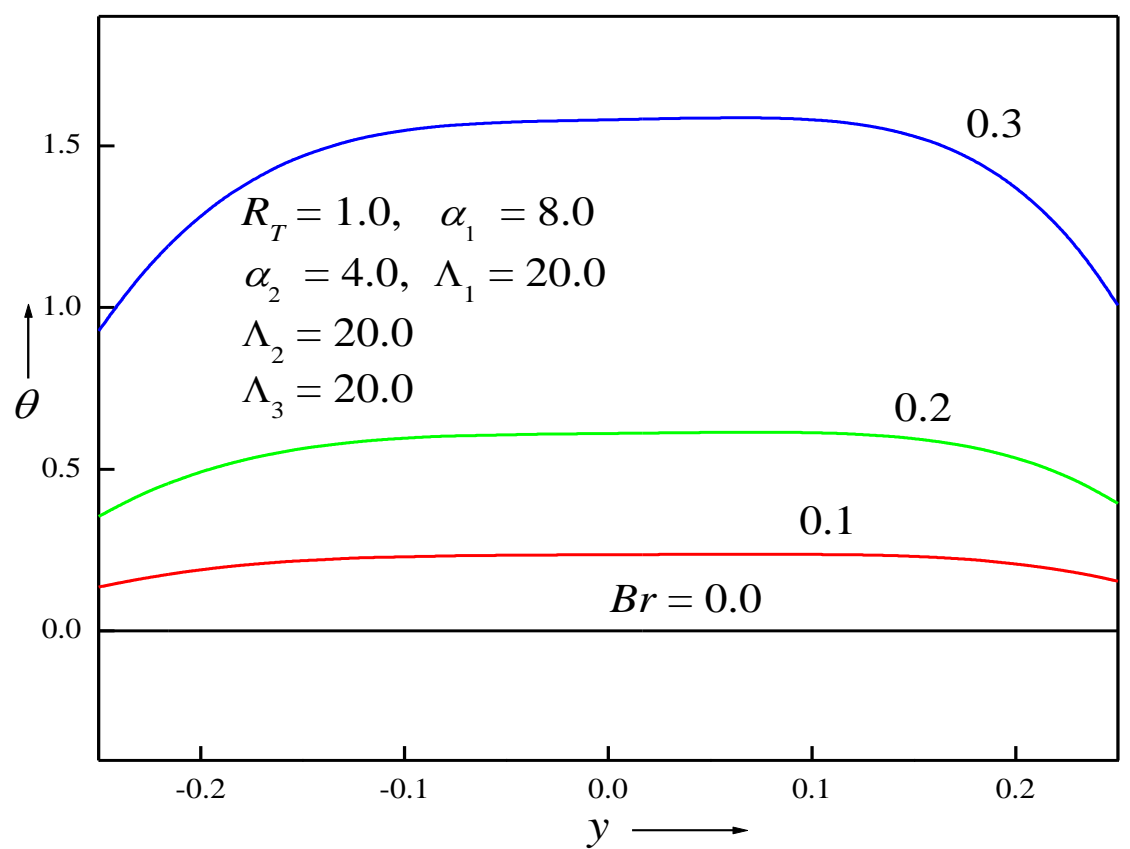

Fig. 8b Plots of $\theta$ versu $B r$ for $B i_{1}=10$ and $B i_{2}=10$

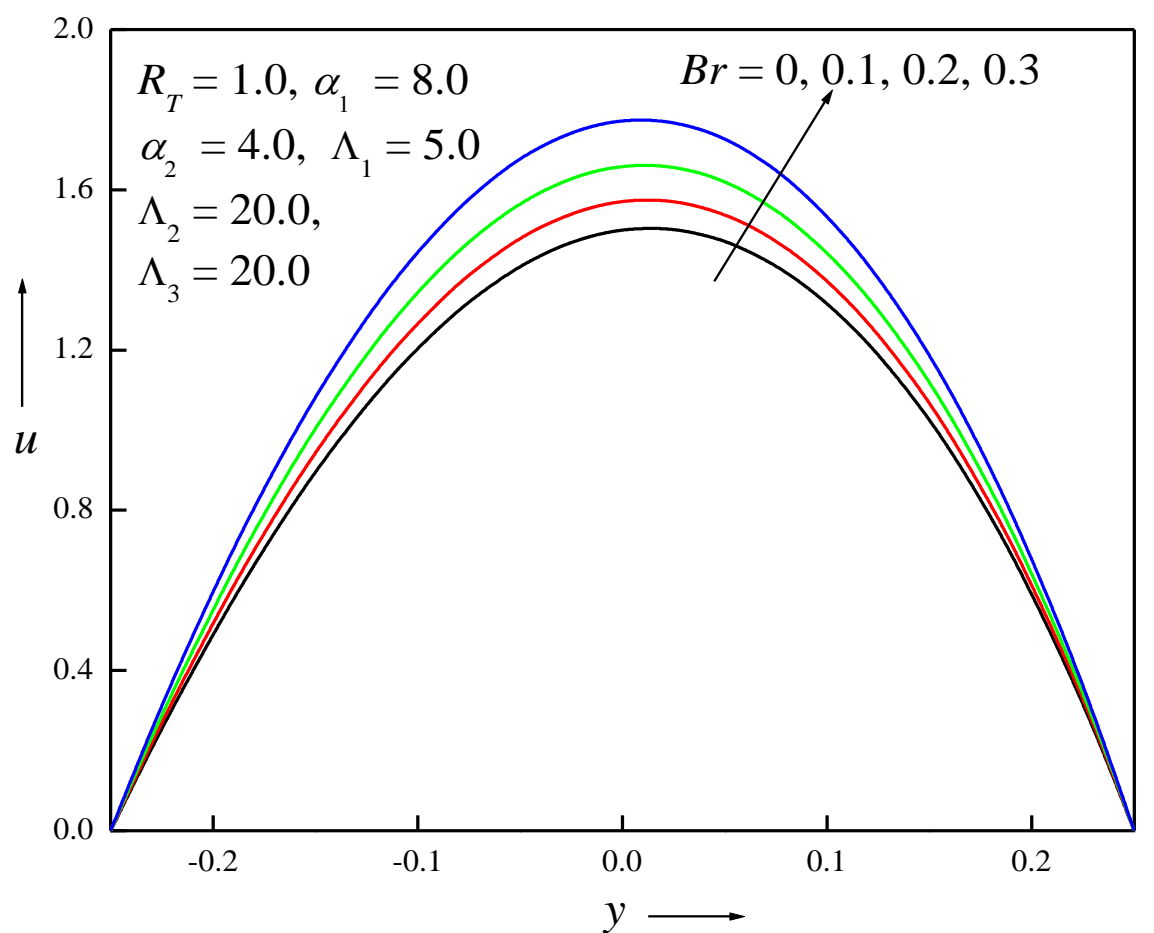

Fig. 8c Plots of $u$ versus $B r$ for $B i_{1}=1$ and $B i_{2}=10$ 


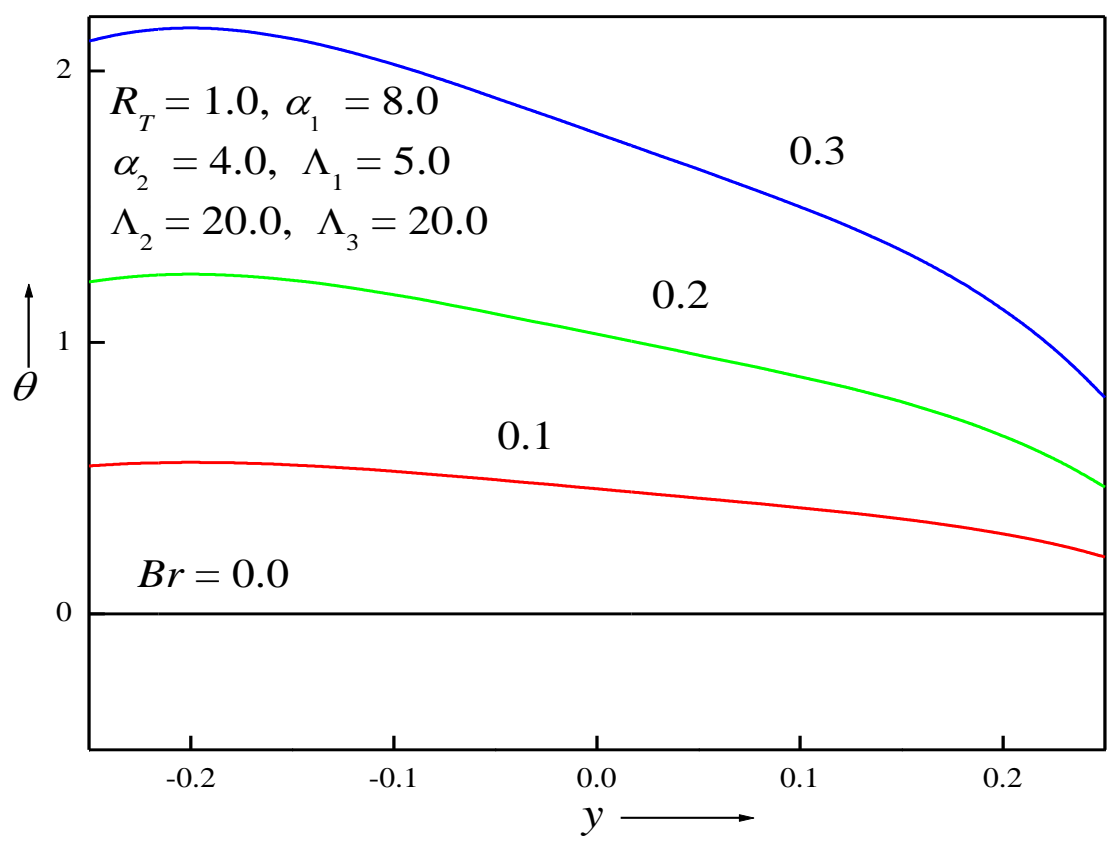

Fig. 8d Plots of $\theta$ versus $B r$ for $B i_{1}=1$ and $B i_{2}=10$

Table 1. Skin friction and Nusselt number at the left and right duct plates for $R_{T}=1.0, B r=0.1, \Lambda_{1}=5.0, \Lambda_{2}=5.0, \Lambda_{3}=5.0, \alpha_{1}=8.0, \alpha_{2}=4.0$

\begin{tabular}{|c|c|c|c|c|}
\hline & \multicolumn{4}{|c|}{$B i_{1}=10, B i_{2}=10$} \\
\hline & $\tau_{1}$ & $\tau_{2}$ & $N u_{1}$ & $N u_{2}$ \\
\hline$\Lambda_{1}$ & & & & \\
\hline 0 & 11.63644210 & -12.36355790 & 2.60962118 & 0.20844988 \\
\hline 10 & 11.82524916 & -13.15551275 & 2.69729604 & 0.08323700 \\
\hline 15 & 11.95385655 & -13.58886517 & 2.75036449 & 0.00984796 \\
\hline 20 & 12.11168602 & -14.05381608 & 2.81146537 & -0.07283766 \\
\hline$\Lambda_{2}$ & & & & \\
\hline 0 & 11.88898360 & -12.57995313 & 2.65895729 & 0.15853630 \\
\hline 10 & 11.55256962 & -12.91697760 & 2.64280181 & 0.13924726 \\
\hline 15 & 11.38443289 & -13.08556013 & 2.63508747 & 0.12923799 \\
\hline 20 & 11.21634302 & -13.25418965 & 2.62761544 & 0.11898555 \\
\hline
\end{tabular}




\begin{tabular}{|c|c|c|c|c|c|}
\hline$\Lambda_{3}$ & \multicolumn{5}{|c|}{} \\
\hline 0 & 11.91681945 & -12.55206386 & 2.66109157 & 0.16093025 \\
\hline 10 & 11.52476206 & -12.94489515 & 2.64080545 & 0.13671486 \\
\hline 15 & 11.32884610 & -13.14142364 & 2.63123277 & 0.12403479 \\
\hline 20 & 11.13300526 & -13.33802735 & 2.62204001 & 0.11097281 \\
\hline$B r$ & \multicolumn{5}{|c|}{} \\
\hline 0 & 11.48763257 & -12.51236743 & 1.42857143 & 1.42857143 \\
\hline 0.1 & 11.72075317 & -12.74844190 & 2.65075832 & 0.14901328 \\
\hline 0.25 & 12.11047181 & -13.14286914 & 4.69449109 & -1.98618051 \\
\hline 0.5 & 12.90468183 & -13.94587444 & 8.86136730 & -6.32392771 \\
\hline$\alpha_{1}$ & \multicolumn{5}{|l|}{} \\
\hline 0 & 11.68020884 & -12.78911374 & 2.64774823 & 0.14538452 \\
\hline 4 & 11.69293323 & -12.77634707 & 2.64870125 & 0.14654189 \\
\hline 8 & 11.72075317 & -12.74844190 & 2.65075832 & 0.14901328 \\
\hline 12 & 11.74882301 & -12.72029648 & 2.65277004 & 0.15139614 \\
\hline$\alpha_{2}$ & & & & \\
\hline 0 & 11.70802713 & -12.76120691 & 2.64979760 & 0.14786362 \\
\hline 4 & 11.72075317 & -12.74844190 & 2.65075832 & 0.14901328 \\
\hline 8 & 11.74857664 & -12.72054025 & 2.65283186 & 0.15146820 \\
\hline 12 & 11.77664982 & -12.69239816 & 2.65485936 & 0.15383514 \\
\hline & & $B i_{1}=1$, & $B i_{2}=10$ & \\
\hline$\Lambda_{1}$ & & & & \\
\hline 0 & 11.63644210 & -12.36355790 & 1.14170926 & -1.25946204 \\
\hline 10 & 12.94321405 & -13.59384092 & 1.26121865 & -1.68561217 \\
\hline 15 & 13.91568565 & -14.45111177 & 1.35598003 & -2.01892221 \\
\hline 20 & 15.33953400 & -15.64938347 & 1.50422633 & -2.53478962 \\
\hline$\Lambda_{2}$ & & & \\
\hline 0 & 12.38477845 & -12.75405262 & 1.19746070 & -1.44097390 \\
\hline 10 & 12.04251638 & -13.08741398 & 1.18950813 & -1.44909545 \\
\hline & & & \\
\end{tabular}




\begin{tabular}{|c|l|l|l|l|}
\hline 15 & 11.87158050 & -13.25424303 & 1.18570418 & -1.45376044 \\
\hline 20 & 11.70077463 & -13.42117105 & 1.18201499 & -1.45882814 \\
\hline$\Lambda_{3}$ & \multicolumn{5}{|c|}{} \\
\hline 0 & 12.41338676 & -12.72664693 & 1.19851018 & -1.44005328 \\
\hline 10 & 12.01398385 & -13.11487763 & 1.18852413 & -1.45024547 \\
\hline 15 & 11.81459123 & -13.30922847 & 1.18380165 & -1.45628978 \\
\hline 20 & 11.61540404 & -13.50373598 & 1.17925903 & -1.46296613 \\
\hline$B r$ & & & & \\
\hline 0 & 11.57133793 & -12.42866207 & 0.62500000 & 0.62500000 \\
\hline 0.1 & 12.21358229 & -12.92068379 & 1.19342690 & -1.44483325 \\
\hline 0.25 & 13.49505445 & -13.89837386 & 2.33101686 & -5.52667068 \\
\hline 0.5 & 18.33790364 & -17.56085394 & 6.65732410 & -20.56710445 \\
\hline$\alpha_{1}$ & & & & \\
\hline 0 & 18.27140133 & -17.58520357 & 6.63104609 & -20.52664758 \\
\hline 4 & 18.29233277 & -17.57759000 & 6.63935705 & -20.53937349 \\
\hline 8 & 18.33790364 & -17.56085394 & 6.65732410 & -20.56710445 \\
\hline 12 & 18.38337221 & -17.54369172 & 6.67492830 & -20.59455369 \\
\hline$\alpha_{2}$ & & & & \\
\hline 0 & 18.31687338 & -17.56839473 & 6.64892406 & -20.55410023 \\
\hline 4 & 18.33790364 & -17.56085394 & 6.65732410 & -20.56710445 \\
\hline 8 & 18.38368728 & -17.54427452 & 6.67548309 & -20.59543434 \\
\hline 12 & 18.42936268 & -17.52726450 & 6.69327405 & -20.62346544 \\
\hline
\end{tabular}

Table 2a. Comparison of solutions obtained by regular perturbation method (RPM) and Runge-Kutta-Shooting method (RKS) for equal Biot numbers

$$
B i_{1}=10, B i_{2}=10, R_{T}=1.0, B r=0.1, \Lambda_{1}=5.0, \Lambda_{2}=5.0, \Lambda_{3}=5.0, \alpha_{1}=8.0, \alpha_{2}=4.0
$$

\begin{tabular}{|l|l|l|l|}
\hline & \multicolumn{3}{|c|}{ Velocity } \\
\hline & $B r=0.0$ & $B r=0.01$ & $B r=0.5$ \\
\hline
\end{tabular}




\begin{tabular}{|c|c|c|c|c|c|c|}
\hline$y$ & RPM & RKS & RPM & RKS & RPM & RKS \\
\hline-0.25 & 0.0 & 0.0 & 0.0 & 0.0 & 0.0 & 0.0 \\
\hline-0.15 & 0.936574 & 0.936573 & 0.935955 & 0.938451 & 0.905658 & 1.055004 \\
\hline-0.05 & 1.428560 & 1.428558 & 1.428360 & 1.431416 & 1.418400 & 1.608754 \\
\hline 0.05 & 1.451440 & 1.451441 & 1.451240 & 1.454305 & 1.441340 & 1.632003 \\
\hline 0.15 & 0.983426 & 0.983426 & 0.982835 & 0.985317 & 0.953839 & 1.102644 \\
\hline 0.25 & 0.0 & 0.0 & 0.0 & 0.0 & 0.0 & 0.0 \\
\hline & \multicolumn{6}{|c|}{ Temperature } \\
\hline & \multicolumn{2}{|c|}{$B r=0.0$} & \multicolumn{2}{|c|}{$B r=0.01$} & \multicolumn{2}{|c|}{$B r=0.5$} \\
\hline$y$ & RPM & RKS & RPM & RKS & RPM & RKS \\
\hline-0.25 & -0.357152 & -0.357142 & -0.35741 & -0.345364 & -0.370053 & 0.386136 \\
\hline-0.15 & -0.214291 & -0.214285 & -0.206839 & -0.195882 & 0.158344 & 0.947026 \\
\hline-0.05 & -0.071430 & -0.071428 & -0.063048 & -0.051888 & 0.347649 & 1.160873 \\
\hline 0.05 & 0.071430 & 0.071428 & 0.079282 & 0.091063 & 0.464049 & 1.309079 \\
\hline 0.15 & 0.214291 & 0.214285 & 0.220952 & 0.233122 & 0.547328 & 1.400272 \\
\hline 0.25 & 0.357152 & 0.357142 & 0.358021 & 0.369483 & 0.400587 & 1.132392 \\
\hline & \multicolumn{6}{|c|}{ Concentration $\phi_{1}$} \\
\hline & \multicolumn{2}{|c|}{$B r=0.0$} & \multicolumn{2}{|c|}{$B r=0.01$} & \multicolumn{2}{|c|}{$B r=0.5$} \\
\hline$y$ & RPM & RKS & RPM & RKS & RPM & RKS \\
\hline-0.25 & -0.5 & -0.5 & -0.5 & -0.5 & -0.5 & -0.5 \\
\hline-0.15 & -0.208095 & -0.208094 & -0.208095 & -0.208094 & -0.208095 & -0.208094 \\
\hline-0.05 & -0.056626 & -0.056626 & -0.056626 & -0.056626 & -0.056626 & -0.056626 \\
\hline 0.05 & 0.056626 & 0.056626 & 0.056626 & 0.056626 & 0.056626 & 0.056626 \\
\hline 0.15 & 0.208095 & 0.208094 & 0.208095 & 0.208094 & 0.208095 & 0.208094 \\
\hline \multirow[t]{3}{*}{0.25} & 0.5 & 0.5 & 0.5 & 0.5 & 0.5 & 0.5 \\
\hline & \multicolumn{6}{|c|}{ Concentration $\phi_{2}$} \\
\hline & \multicolumn{2}{|c|}{$B r=0.0$} & \multicolumn{2}{|c|}{$B r=0.01$} & \multicolumn{2}{|c|}{$B r=0.5$} \\
\hline$y$ & RPM & RKS & RPM & RKS & RPM & RKS \\
\hline-0.25 & -0.5 & -0.5 & -0.5 & -0.5 & -0.5 & -0.5 \\
\hline-0.15 & -0.270870 & -0.270870 & -0.270870 & -0.270870 & -0.270870 & -0.270870 \\
\hline
\end{tabular}




\begin{tabular}{|c|c|c|c|c|c|c|}
\hline-0.05 & -0.085660 & -0.085660 & -0.085660 & -0.085660 & -0.085660 & -0.085660 \\
\hline 0.05 & 0.085660 & 0.085660 & 0.085660 & 0.085660 & 0.085660 & 0.085660 \\
\hline 0.15 & 0.270870 & 0.270870 & 0.270870 & 0.270870 & 0.270870 & 0.270870 \\
\hline 0.25 & 0.5 & 0.5 & 0.5 & 0.5 & 0.5 & 0.5 \\
\hline
\end{tabular}

Table 2b. Comparison of solutions obtained by (RPM) and (RKS) for unequal Biot numbers for $B i_{1}=1, B i_{2}=10, R_{T}=1.0, B r=0.1, \Lambda_{1}=5.0, \Lambda_{2}=5.0, \Lambda_{3}=5.0, \alpha_{1}=8.0$, $\alpha_{2}=4.0$

\begin{tabular}{|c|c|c|c|c|c|c|}
\hline & \multicolumn{6}{|c|}{ Velocity $u$} \\
\hline & \multicolumn{2}{|c|}{$B r=0.0$} & \multicolumn{2}{|c|}{$B r=0.01$} & \multicolumn{2}{|c|}{$B r=0.5$} \\
\hline$y$ & RPM & RKS & RPM & RKS & RPM & RKS \\
\hline-0.25 & 0.0 & 0.0 & 0.0 & 0.0 & 0.0 & 0.0 \\
\hline-0.15 & 0.940592 & 0.940591 & 0.939987 & 0.944564 & 0.910342 & 1.410176 \\
\hline-0.05 & 1.430570 & 1.430567 & 1.430430 & 1.436914 & 1.423920 & 2.181920 \\
\hline 0.05 & 1.449430 & 1.449432 & 1.449300 & 1.456132 & 1.442800 & 2.243588 \\
\hline 0.15 & 0.979408 & 0.979408 & 0.978806 & 0.984087 & 0.949282 & 1.534794 \\
\hline \multirow[t]{3}{*}{0.25} & 0.0 & 0.0 & 0.0 & 0.0 & 0.0 & 0.0 \\
\hline & \multicolumn{6}{|c|}{ Temperature $\theta$} \\
\hline & \multicolumn{2}{|c|}{$B r=0.0$} & \multicolumn{2}{|c|}{$B r=0.01$} & \multicolumn{2}{|c|}{$B r=0.5$} \\
\hline$y$ & RPM & RKS & RPM & RKS & RPM & RKS \\
\hline-0.25 & -0.156250 & -0.156250 & -0.156179 & -0.137420 & -0.152703 & 2.034805 \\
\hline-0.15 & -0.093750 & -0.093750 & -0.085551 & -0.061324 & 0.316172 & 3.714352 \\
\hline-0.05 & -0.013250 & -0.031250 & -0.021712 & 0.009240 & 0.445634 & 4.756959 \\
\hline 0.05 & 0.031250 & 0.031250 & 0.040688 & 0.078769 & 0.503191 & 5.668512 \\
\hline 0.15 & 0.093750 & 0.093750 & 0.102422 & 0.147390 & 0.527344 & 6.479817 \\
\hline \multirow[t]{3}{*}{0.25} & 0.156250 & 0.156250 & 0.159587 & 0.210303 & 0.323083 & 6.609540 \\
\hline & \multicolumn{6}{|c|}{ Concentration $\phi_{1}$} \\
\hline & \multicolumn{2}{|c|}{$B r=0.0$} & \multicolumn{2}{|c|}{$B r=0.01$} & \multicolumn{2}{|c|}{$B r=0.5$} \\
\hline$y$ & RPM & RKS & RPM & RKS & RPM & RKS \\
\hline
\end{tabular}




\begin{tabular}{|c|c|c|c|c|c|c|}
\hline-0.25 & -0.5 & -0.5 & -0.5 & -0.5 & -0.5 & -0.5 \\
\hline-0.15 & -0.208095 & -0.208094 & -0.208095 & -0.208094 & -0.208095 & -0.208094 \\
\hline-0.05 & -0.056626 & -0.056626 & -0.056626 & -0.056626 & -0.056626 & -0.056626 \\
\hline 0.05 & 0.056626 & 0.056626 & 0.056626 & 0.056626 & 0.056626 & 0.056626 \\
\hline 0.15 & 0.208095 & 0.208094 & 0.208095 & 0.208094 & 0.208095 & 0.208094 \\
\hline 0.25 & 0.5 & 0.5 & 0.5 & 0.5 & 0.5 & 0.5 \\
\hline & & & Concentration $\phi_{2}$ & & \\
\hline & \multicolumn{2}{|c|}{$B r=0.0$} & \multicolumn{2}{|c|}{$B r=0.01$} & \multicolumn{2}{|c|}{$B r=0.5$} \\
\hline$y$ & $\mathrm{RPM}$ & $\mathrm{RKS}$ & $\mathrm{RPM}$ & $\mathrm{RKS}$ & $\mathrm{RPM}$ & $\mathrm{RKS}$ \\
\hline-0.25 & -0.5 & -0.5 & -0.5 & -0.5 & -0.5 & -0.5 \\
\hline-0.15 & -0.270870 & -0.270870 & -0.270870 & -0.270870 & -0.270870 & -0.270870 \\
\hline-0.05 & -0.085660 & -0.085660 & -0.085660 & -0.085660 & -0.085660 & -0.085660 \\
\hline 0.05 & 0.085660 & 0.085660 & 0.085660 & 0.085660 & 0.085660 & 0.085660 \\
\hline 0.15 & 0.270870 & 0.270870 & 0.270870 & 0.270870 & 0.270870 & 0.270870 \\
\hline 0.25 & 0.5 & 0.5 & 0.5 & 0.5 & 0.5 & 0.5 \\
\hline
\end{tabular}

